\title{
Single Amino Acid Mutations in the Potato Immune Receptor R3a Expand Response to Phytophthora Effectors
}

\author{
María Eugenia Segretin, ${ }^{1,2}$ Marina Pais, ${ }^{1}$ Marina Franceschetti, ${ }^{3}$ Angela Chaparro-Garcia, \\ Jorunn I. B. Bos, ${ }^{1}$ Mark J. Banfield, ${ }^{3}$ and Sophien Kamoun ${ }^{1}$
}

${ }^{1}$ The Sainsbury Laboratory, Norwich Research Park, Norwich, NR4 7UH, U.K.; ${ }^{2}$ Instituto de Investigaciones en Ingeniería Genética y Biología Molecular, Consejo Nacional de Investigaciones Científicas y Técnicas, Buenos Aires, C1428ADN, Argentina; ${ }^{3}$ Department of Biological Chemistry, John Innes Centre, Norwich Research Park, Norwich, NR4 7UH, U.K.

Submitted 12 February 2014. Accepted 13 March 2014.

Both plants and animals rely on nucleotide-binding domain and leucine-rich repeat-containing (NB-LRR or NLR) proteins to respond to invading pathogens and activate immune responses. How plant NB-LRR proteins respond to pathogens is poorly understood. We undertook a gain-of-function random mutagenesis screen of the potato NB-LRR immune receptor $\mathrm{R3a}$ to study how this protein responds to the effector protein AVR3a from the oomycete pathogen Phytophthora infestans. R3a response can be extended to the stealthy AVR3a ${ }^{\mathrm{EM}}$ isoform of the effector while retaining recognition of $A V R 3 a^{\mathrm{KI}}$. Each one of eight single amino acid mutations is sufficient to expand the $R 3 a$ response to AVR3a $^{\text {EM }}$ and other AVR3a variants. These mutations occur across the $\mathbf{R} 3$ a protein, from the $\mathbf{N}$ terminus to different regions of the LRR domain. Further characterization of these R3a mutants revealed that at least one of them was sensitized, exhibiting a stronger response than the wild-type R3a protein to AVR3a ${ }^{\mathrm{KI}}$. Remarkably, the N336Y mutation, near the R3a nucleotide-binding pocket, conferred response to the effector protein PcAVR3a4 from the vegetable pathogen $P$. capsici. This work contributes to understanding how NB-LRR receptor specificity can be modulated. Together with knowledge of pathogen effector diversity, this strategy can be exploited to develop synthetic immune receptors.

Plant diseases represent a significant threat to human welfare, resulting in economic hardship, malnutrition, famine, and environmental degradation. Among the diverse plant pathogens, filamentous eukaryotic microorganisms such as oomycetes and fungi cause the most destructive crop diseases and are a recurrent threat to world food security (Fisher et al. 2012). The oomycete genus Phytophthora ("plant destroyer" in Greek) includes the most devastating pathogens of dicot plants (Fry 2008). More than 100 species of Phytophthora are known, including the notorious Irish potato famine pathogen Phytoph-

M. E. Segretin and M. Pais contributed equally to this work as first authors.

Corresponding author: S. Kamoun; E-mail: sophien.kamoun@tsl.ac.uk

Current address of J. I. B. Bos: The James Hutton Institute, Invergowrie, Dundee, DD2 5DA, Scotland, U.K.

* The $\boldsymbol{e}$-Xtra logo stands for "electronic extra" and indicates two supplementary figures and one supplementary table are published online.

(C) 2014 The American Phytopathological Society thora infestans (Haas et al. 2009; Kroon et al. 2011; Yoshida et al. 2013). P. infestans, the causative agent of the late blight disease, is considered one of the most important biotic threats to global food security affecting worldwide production of key crops such as potato and tomato (Haverkort et al. 2008). Annual losses of potato harvest due to $P$. infestans would be sufficient to feed from 80 to many hundreds of millions of people and amount to several billion dollars per year (Cavalier-Smith and Chao 2006; Cooke 2013; Fisher et al. 2012; Haas et al. 2009; Kroon et al. 2011; and the Food and Agriculture Organization of the United Nations (FAO) website). P. capsici is another destructive plant pathogen that limits vegetable production in many regions of the world (Lamour et al. 2012). It is the causative agent of blight and fruit rot of pepper and other important commercial crops, including cucurbits, tomato, eggplant, and snap and lima bean (Lamour et al. 2012). Management of Phytophthora diseases in the field is difficult and requires repeated applications of chemicals, some of which might be banned in the near future due to concerns over environmental damage. The most sustainable strategy to manage Phytophthora diseases is to breed broad-spectrum disease resistance with a time-efficient and knowledge-based approach (Vleeshouwers et al. 2011).

Similar to other plant pathogens, oomycetes secrete an arsenal of effector proteins that modulate plant innate immunity and enable host colonization (Bozkurt et al. 2012; Dodds and Rathjen 2010; Hogenhout et al. 2009; Win et al. 2012a). Plants respond to invaders such as $P$. infestans with cell surface and intracellular immunoreceptors that perceive pathogen molecules and activate effective immune responses. Intracellular immune receptors belong to the nucleotide-binding leucinerich repeat-containing (NB-LRR or NLR) protein family that mediates pathogen immunity in both plants and animals (Jacob et al. 2013; Maekawa et al. 2011b). In plants, NB-LRR proteins typically recognize specific effectors and activate a response known as NB-LRR-triggered immunity or effectortriggered immunity (Dodds and Rathjen 2010; Jones and Dangl 2006; van Ooijen et al. 2007; Win et al. 2012a). Two classes of phylogenetically distinct NB-LRR receptor proteins are defined based on the occurrence of the coiled-coil (CC) or Toll/interleukin-1 receptor domains (Jupe et al. 2012). In most cases, activation of NB-LRR receptors leads to a cell death response known as the hypersensitive response (HR), a defense reaction that can restrict the invading pathogen (Kamoun et al. 1999; Vleeshouwers et al. 2000; Win et al. 2012a). Plant pathogens such as $P$. infestans are engaged in a co-evolutionary 
arms race with their host plants, and are continuously evolving new effector variants to evade NB-LRR immunity or suppress host defenses (Fry 2008; Win et al. 2012a).

To date, over 20 disease resistance $(R)$ genes that function against $P$. infestans isolates have been cloned from various wild potato lines (Solanum spp.). All of these late blight $R$ genes belong to the CC-NB-LRR class of NB-LRR receptor proteins and many occur in complex genetic loci (Jupe et al. 2012; Vleeshouwers et al. 2011). The Solanum demissum genes $R 1, R 2, R 3, R 4$, and $R 10$ have been bred into cultivated potato lines during the 20th century and have been widely used in conventional plant breeding programs (Vleeshouwers et al. 2011). However, these resistance genes have been rapidly defeated by new virulent races of $P$. infestans and are of limited value in modern agriculture (Fry and Goodwin 1997; Umaerus and Umaerus 1994; Wastie 1991).

One of the first late blight $R$ genes to be bred in potato is $R 3 a$, which recognizes specific forms of $P$. infestans AVR3a, a host-translocated effector that belongs to the RXLR class of oomycete effectors (Armstrong et al. 2005; Birch et al. 2008; Huang et al. 2005; Morgan and Kamoun 2007). Two major Avr3a alleles occur in $P$. infestans populations. They encode AVR $3 \mathrm{a}^{\mathrm{K} 80 / 1103}\left(\mathrm{AVR} 3 \mathrm{a}^{\mathrm{KI}}\right.$ ) and AVR3 $\mathrm{a}^{\mathrm{E} 80 / \mathrm{M} 103}$ (AVR3a ${ }^{\mathrm{EM}}$ ), which differ in two amino acids in their effector domains. R3a responds to AVR $3 \mathrm{a}^{\mathrm{KI}}$ but only weakly to AVR $3 \mathrm{a}^{\mathrm{EM}}$, and races of $P$. infestans that are virulent on R3a potato plants are homozygous for the $A V R 3 a^{E M}$ allele (Armstrong et al. 2005; Bos et al. 2006, 2009). $A V R 3 a^{E M}$ is the most prevalent allele in modern populations of $P$. infestans and the frequency of this allele has increased in the $P$. infestans population since the 19th century pandemic (Armstrong et al. 2005; Bos et al. 2009, 2010; Vleeshouwers et al. 2011; Yoshida et al. 2013). As a consequence, the $R 3 a$ gene does not confer resistance to the majority of $P$. infestans strains that occur in modern agricultural systems.

The $P$. infestans AVR3a effector is a member of a large family of RXLR effectors that occur in most Phytophthora spp., including the pepper pathogen $P$. capsici and the soybean pathogen P. sojae (Bos et al. 2009; Haas et al. 2009; Tyler et al. 2006). Similar to other oomycete RXLR effectors, AVR3a proteins are modular, with the N-terminal region implicated in secretion and host translocation (Birch et al. 2008; Morgan and Kamoun 2007). The C-terminal domain carries the biochemical effector activity and is characterized by the WY $\alpha$-helical fold that occurs in approximately $40 \%$ of Phytophthora RXLR effectors (Boutemy et al. 2011; Win et al. 2012b; Wirthmueller et al. 2013). The majority of AVR3a family proteins, except for $P$. sojae AVH1b, do not elicit R3a-dependent hypersensitive cell death (Win et al. 2007). However, given their conservation across Phytophthora spp. and importance in pathogen virulence, AVR3a family effectors should be good targets for NBLRR-mediated disease resistance. Indeed, $P$. sojae AVR1b, an AVR3a homolog, is known to mediate resistance in soybean plants carrying the NB-LRR gene Rpslb (Dou et al. 2008).

Although NB-LRR immune receptors have been known in plants for approximately 20 years, our mechanistic understanding of their function remains incomplete (Elmore et al. 2011; Maekawa et al. 2011b; Takken and Goverse 2012). According to current models of effector recognition, NB-LRR proteins can directly bind pathogen effectors or perceive them indirectly via effector-mediated modifications of plant proteins, that can be either guardees (virulence targets of the effectors) or decoys (mimics of effector virulence targets) (Elmore et al. 2011; Takken and Goverse 2012; van der Hoorn and Kamoun 2008). The multidomain architecture of NB-LRR proteins enables them to operate as both pathogen sensors and activators of immune signaling (Takken and Goverse 2012). Intramolecular interactions between the different domains of NB-LRR pro- teins are important in maintaining them in an autoinhibited state that can be perturbed by pathogen effectors (Maekawa et al. 2011b; Takken and Goverse 2012). The NB domain, also known as NB-ARC (NB adaptor shared with APAF-1, plant resistance proteins, and CED-4), is thought to act as a molecular switch modulated by conformational changes and the replacement of ADP by ATP (Maekawa et al. 2011b; Takken and Goverse 2012). Recently, crystal structures of individual domains of plant NB-LRR proteins have begun to emerge (Bernoux et al. 2011; Hao et al. 2013; Maekawa et al. 2011a). Furthermore, the first structural insights into how different domains of NB-LRR proteins fold together have been obtained for the mouse protein NLRC4 but structural data of full-length plant NB-LRR receptors is still lacking (Hu et al. 2013).

A better understanding of NB-LRR protein structure and function would be useful to rationally design receptors with altered specificity. Previous studies have taken advantage of natural variation of $\mathrm{R}$ proteins and knowledge on NB-LRR structure to modify receptor specificity (Steinbrenner et al. 2012; Stirnweis et al. 2013). However, this strategy presents limitations and other methodologies are required when such natural variation is not available. An alternative approach is to screen randomly mutagenized NB-LRR proteins to recover variants with altered recognition properties. Such synthetic mutations may directly affect effector recognition specificity or result in sensitized (i.e., trigger-happy) NB-LRR receptors with a lower threshold for activation. Thus far, random mutagenesis has only been applied to the potato NB-LRR protein Rx in a domain-specific and stepwise manner (Farnham and Baulcombe 2006; Harris et al. 2013). Mutations in the LRR domain of $\mathrm{Rx}$ confer extended recognition against hitherto unrecognized strains of Potato virus $X$ and Poplar mosaic virus (PopMV) (Farnham and Baulcombe 2006). Mutations that enhance activation sensitivity were recovered in a second round of mutagenesis, which focused on the $\mathrm{N}$-terminal domain (Harris et al. 2013). These additional mutations near the NB pocket of Rx enhanced the response conferred by a single mutation in the LRR domain, resulting in resistance to PopMV (Harris et al. 2013).

In this study, we have extended the response spectrum of R3a to include the stealthy $P$. infestans AVR3a isoform AVR $3 \mathrm{a}^{\mathrm{EM}}$. To accomplish this, we screened a library of R3a variants obtained by random mutagenesis of the full-length $R 3 a$ coding sequence, and recovered mutants that trigger hypersensitivity toward AVR $3 \mathrm{a}^{\mathrm{EM}}$ while retaining recognition of AVR $3 \mathrm{a}^{\mathrm{KI}}$. We implemented the screen based on previous findings showing that the interaction between AVR3a and R3a can be reconstructed by concurrent expression in the model plant species Nicotiana benthamiana using Agrobacterium tumefaciens transient assays (agroinfiltration) (Armstrong et al. 2005; Bos et al. 2006). Single amino acid mutations that expand response to AVR $3 \mathrm{a}^{\mathrm{EM}}$ were recovered in all three domains of R3a. One mutant R3 $\mathrm{a}^{\mathrm{L} 668 \mathrm{P}}$, carrying a substitution in the $\mathrm{N}$-terminal region of the LRR domain, responds to AVR $3 \mathrm{a}^{\mathrm{KI}}$ more efficiently than the wild-type R3a. Remarkably, another R3a mutant, $\mathrm{R} 3 \mathrm{a}^{\mathrm{N} 336 \mathrm{Y}}$, with an amino acid substitution near the NB site, gained the ability to respond to the $P$. capsici effector protein PcAVR3a4. Our work contributes to understanding how NB-LRR receptor specificity can be modulated which, together with knowledge of pathogen effector diversity, can be exploited to develop synthetic immune receptors.

\section{RESULTS}

\section{R3a mutant library and screening strategy.}

To identify $R 3 a$ mutants with expanded effector response, we first generated synthetic (non-natural) variants by polymerase chain reaction (PCR)-based random mutagenesis. We used 


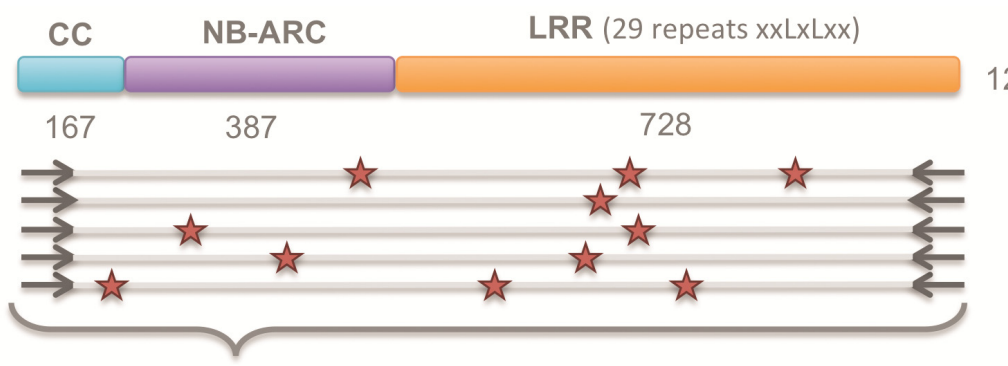

Cloning in binary vector and library construction ( $A$. tumefaciens)

PVX-AVR3aEM (A. tumefaciens)
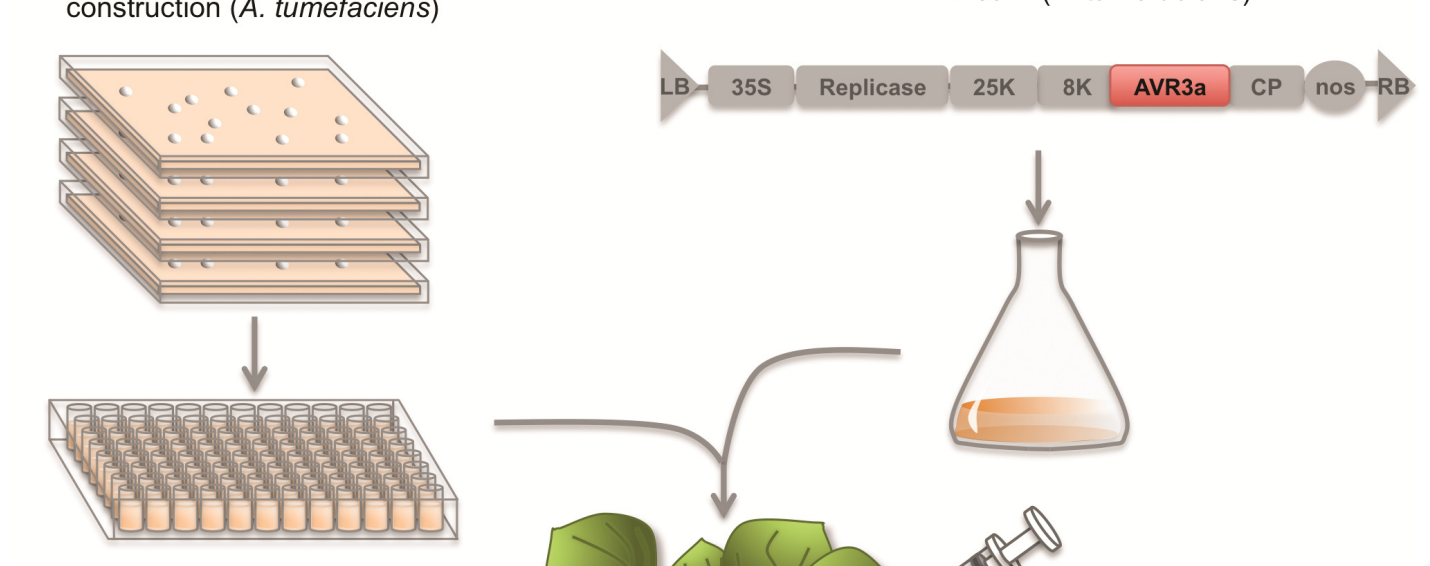

Generation of R3a $\downarrow$ variants by PCR-based random mutagenesis
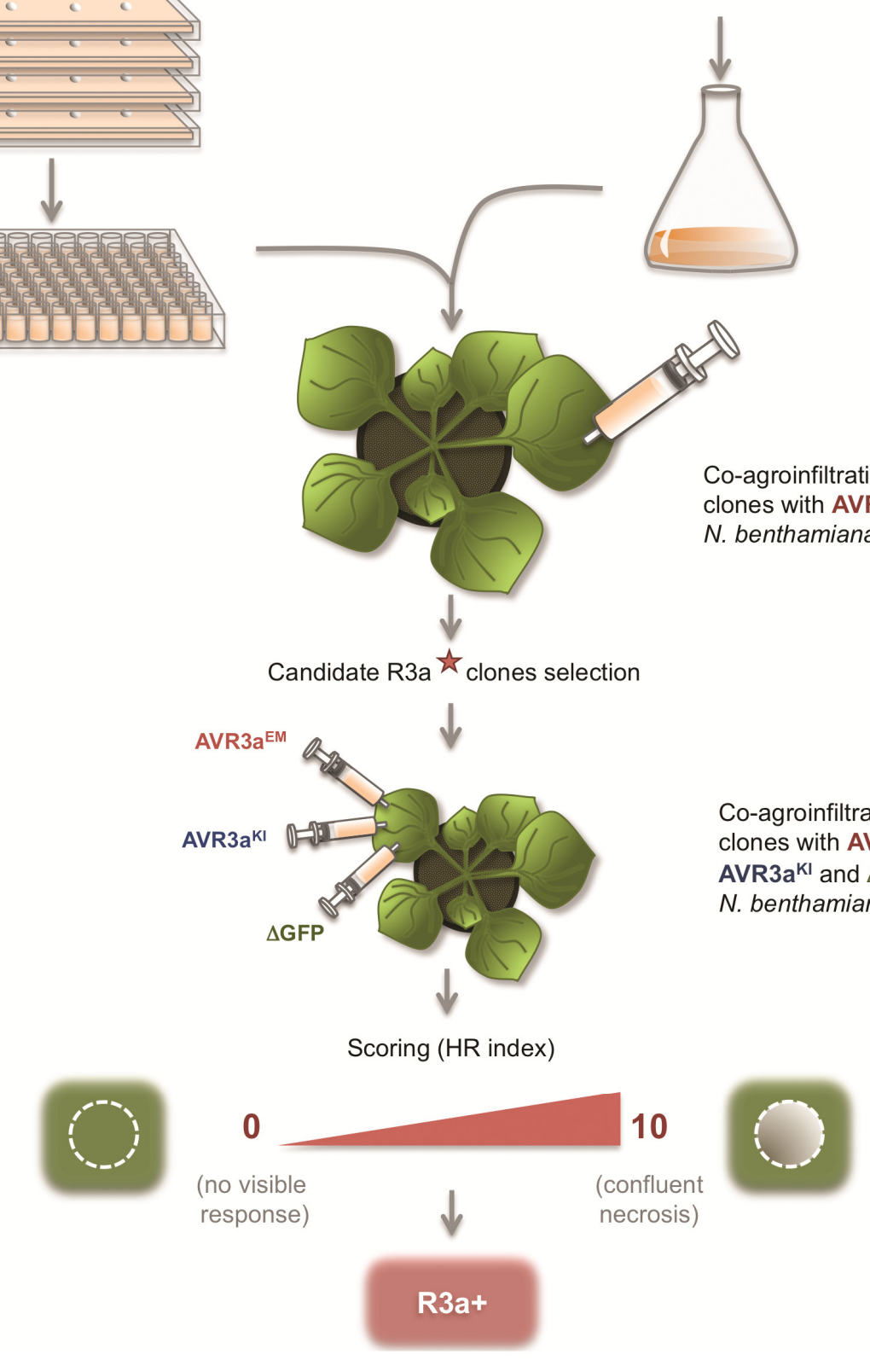

Fig. 1. R3a mutant library construction and screening strategy. The full length $R 3 a$ coding sequence $(3,849 \mathrm{bp})$ was used as template for a polymerase chain reaction-based random mutagenesis. Amplification products were cloned in the binary vector pCB302-3 (under transcriptional control of the Cauliflower mosaic virus $35 \mathrm{~S}$ promoter) and transformed into Agrobacterium tumefaciens. The library was screened for gain-of-function phenotype by co-agroinfiltration in Nicotiana benthamiana of the R3a mutant clones (R3a*) with Phytophthora infestans AVR3a ${ }^{\mathrm{EM}}$ expressed from a Potato virus X (PVX)-based vector. Appearance of hypersensitive response (HR)-like phenotypes was evaluated at 5 days postinfiltration (dpi), and clones showing response to AVR3 $\mathrm{a}^{\mathrm{EM}}$ were selected for a second round of co-infiltrations, including also co-expression with AVR $3 \mathrm{a}^{\mathrm{KI}}$ and with a truncated version of green fluorescent protein $(\Delta \mathrm{GFP})$. Intensity of the observed responses was scored according to an arbitrary scale ranging from 0 (no HR-like phenotype) to 10 (confluent necrosis in the infiltrated area). Clones selected after these steps were named R3a+. 
the full-length $R 3 a$ coding sequence $(3,849 \mathrm{bp})$ as template, and tested different conditions in order to obtain a mutation rate between one and two mutations every 1,000 bp. Mutagenized $R 3 a$ molecules were cloned in the binary vector pCB302-3 (Xiang et al. 1999) under the transcriptional control of the Cauliflower mosaic virus $35 \mathrm{~S}$ promoter, and transformed into A. tumefaciens to generate a library that could be screened by agroinfiltration assays in $N$. benthamiana. The pipeline to screen for R3a mutant clones with expanded response toward P. infestans AVR3a $\mathrm{a}^{\mathrm{EM}}$ is illustrated in Figure 1. Briefly, we screened the mutant clones by co-expression with AVR $3 \mathrm{a}^{\mathrm{EM}}$ in $N$. benthamiana leaves for gain of function assessment. We evaluated appearance of HR-like phenotypes at 5 days postinfiltration (dpi) and selected candidate clones for a second round of co-infiltrations, including co-expression with AVR $3 \mathrm{a}^{\mathrm{KI}}$ to assess whether the R3a mutant clones retained their original activity, and with the negative control (truncated green fluorescent protein $[\Delta \mathrm{GFP}])$ to rule out that the observed cell death was a consequence of auto-activation. We scored the intensity of the observed responses according to an arbitrary scale ranging from 0 (no HR-like phenotype) to 10 (confluent necrosis in the infiltrated area). R3a mutant clones selected after implementation of this pipeline were designated R3a+.

\section{R3a+: R3a mutants that respond to the AVR3a ${ }^{\mathrm{EM}}$ effector.}

We screened approximately 2,200 clones of the R3a mutant library and identified $17 \mathrm{R} 3 \mathrm{a}+$ clones that triggered visible $\mathrm{HR}$ in the presence of AVR3a ${ }^{\mathrm{EM}}$ (Fig. 2A and B). These candidate clones showed different degrees of response toward AVR3 $\mathrm{a}^{\mathrm{EM}}$. The R3a-17+, 18+, and 19+ mutant clones consistently gave the strongest HR with AVR3 $\mathrm{a}^{\mathrm{EM}}$. All $17 \mathrm{R} 3 \mathrm{a}+$ clones retained the ability to respond to AVR3a ${ }^{\mathrm{KI}}$ (Fig. 2B). The majority of the R3a mutants did not trigger any HR symptoms when expressed with the negative control ( $\Delta$ GFP). However, R3a clones $18+$ and $19+$ showed weak responses in some of the infiltrated leaves (HR index typically $<2$ on a scale of 1 to 10 ), indicating some degree of auto-activation (Fig. 2B). Overall, these results indicate that the response of R3a can be expanded toward $P$. infestans effector AVR $3 \mathrm{a}^{\mathrm{EM}}$ without compromising its original recognition of $A V R 3 \mathrm{a}^{\mathrm{KI}}$.

We next sequenced the $17 \mathrm{R} 3 \mathrm{a}+$ clones to determine the underlying mutations. We found that each clone incorporated one to nine nonsynonymous mutations (on average approximately 4 amino-acid substitutions per R3a+ variant) (Fig. 2A). The mutations were distributed along the three NB-LRR protein domains (CC, NB-ARC, and LRR) (Supplementary Table S1). Interestingly, we noted a "hotspot" of amino acid changes around LRR repeats 15 and 18 (LRR repeat numbers throughout the article are based on Huang et al. 2005). This indicates that LRR 15 to 18 could be important for recognition or activation of R3a by AVR3 ${ }^{\mathrm{EM}}$. Particularly, clone R3a-17+ had one single-amino-acid change in the LRR repeat $15\left(\mathrm{~K}^{920}\right.$ to $\left.\mathrm{E}\right)$ compared with the wild-type R3a protein.

\section{Single-amino-acid changes can expand R3a response to AVR3a ${ }^{\text {EM }}$.}

To investigate which specific nonsynonymous mutations are responsible for the new response to AVR $3 \mathrm{a}^{\mathrm{EM}}$, we deconvoluted mutations observed in the original R3a+ clones into singleresidue mutant clones. We co-infiltrated these single-residue
A

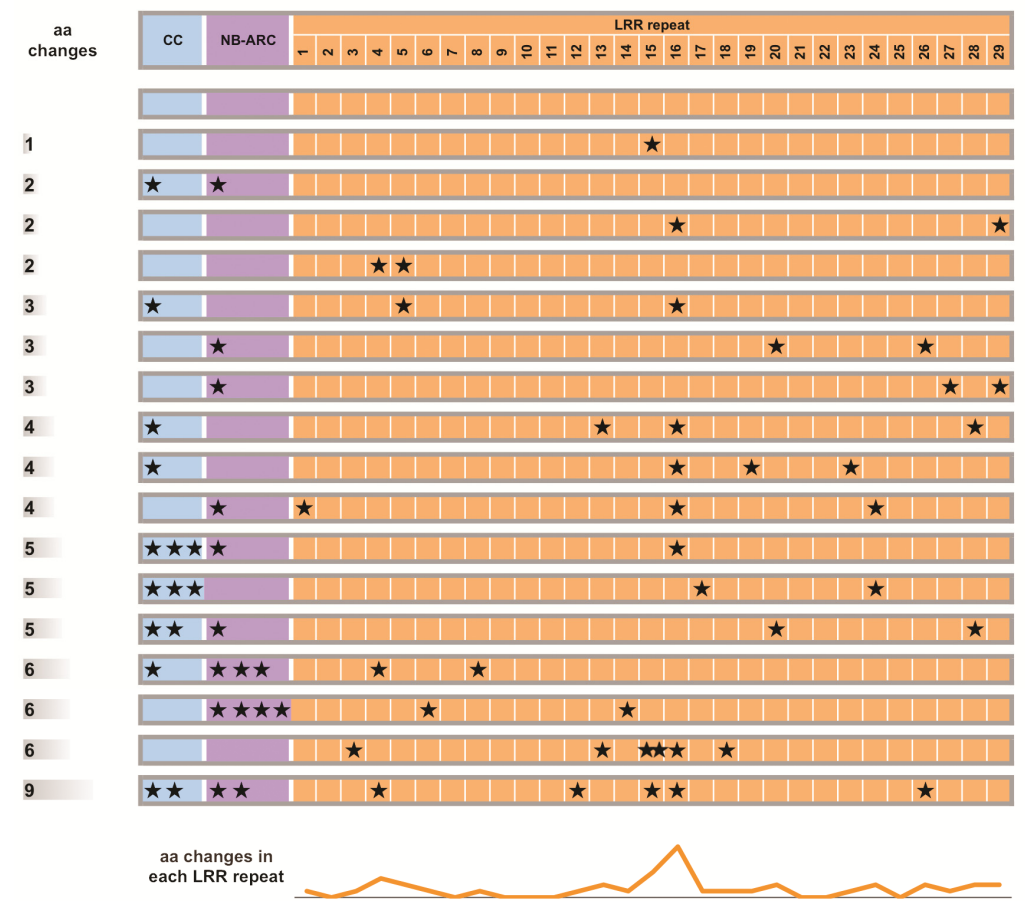

B

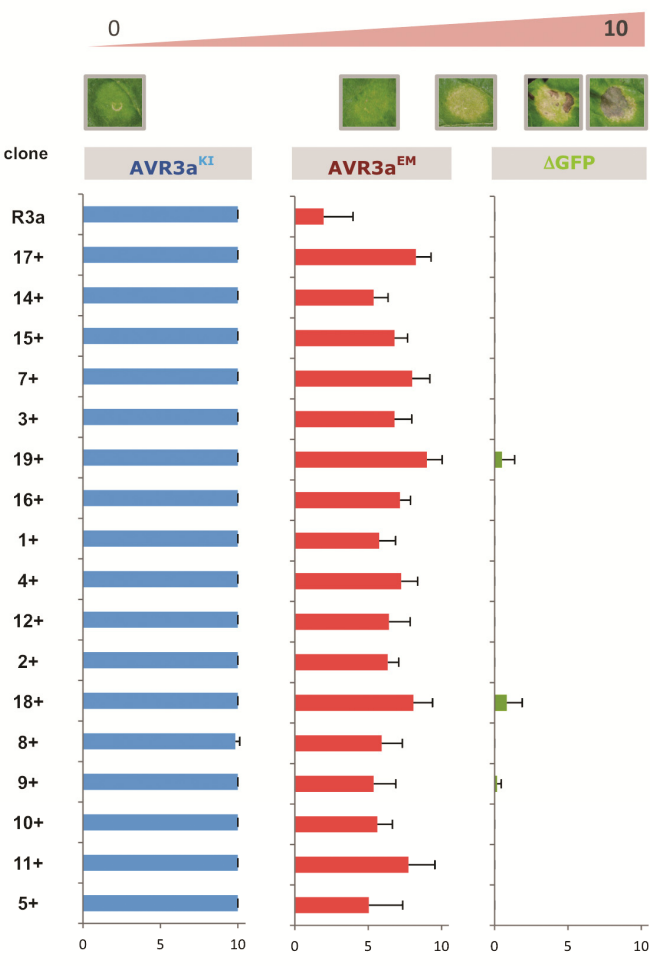

HR Index

Fig. 2. Characterization of selected R3a mutant clones with expanded response to AVR $3 \mathrm{a}^{\mathrm{EM}}$ (R3a+ clones). A, A total of 17 R3a+ clones were fully sequenced. Identified nonsynonymous mutations are indicated with stars positioned in the corresponding nucleotide-binding leucine-rich repeat-containing (NB-LRR) protein domain. Numbers of amino-acid changes related to wild-type R3a are indicated as bars on the left panel; a graph depicting number of amino-acid changes per LRR repeat for the $17 \mathrm{R} 3 \mathrm{a}+$ clones is shown below. B, Hypersensitive response (HR) index scored at 7 days postinfiltration (dpi) after co-agroinfiltration in Nicotiana benthamiana of the R3a+ clones (under transcriptional control of the Cauliflower mosaic virus $35 \mathrm{~S}$ promoter) or wildtype R3a with AVR $3 \mathrm{a}^{\mathrm{EM}}, \mathrm{AVR} 3 \mathrm{a}^{\mathrm{KI}}$, or a truncated version of green fluorescent protein $(\Delta \mathrm{GFP})$ expressed from a Potato virus $X$ (PVX)-based vector. Bars represent the average of 10 replicas; the error bars represent standard deviation. Representative pictures for different values of HR index are included. 
mutant clones with AVR $3 \mathrm{a}^{\mathrm{EM}}$ and scored HR-like phenotypes at $6 \mathrm{dpi}$. We observed that eight single-residue mutants triggered the HR in the presence of AVR $3 \mathrm{a}^{\mathrm{EM}}$ with an HR index of 2 to 9 , depending on the mutant (Fig. 3A). R3a ${ }^{\mathrm{C} 950 \mathrm{R}}$ triggered the weakest response (HR index of approximately 2) whereas all the other mutants gave an HR-index $>5$ (Fig. 3A). All the tested clones retained the ability to trigger the $\mathrm{HR}$ when coinfiltrated with AVR $3 \mathrm{a}^{\mathrm{KI}}$ (Fig. 3A). One of the mutant clones, $\mathrm{R} 3 \mathrm{a}^{\mathrm{I} 148 \mathrm{~F}}$, could also trigger the HR in the presence of the negative control $\Delta$ GFP (HR index of approximately 6), indicating that this mutation confers an auto-activation phenotype to R3a. Overall, these results indicate that single-amino-acid changes in $\mathrm{R} 3 \mathrm{a}$ can expand its response to $P$. infestans AVR $3 \mathrm{a}^{\mathrm{EM}}$.

To date, the three-dimensional structure of a full-length plant NB-LRR protein has not been determined. However, representative structures of each domain (CC, NB-ARC, and LRR) are available from either plant or other eukaryotic proteins. In an attempt to understand the structural consequences of the $\mathrm{R} 3 \mathrm{a}+$ single mutations, we generated homology models of the individual $\mathrm{CC}$, NB-ARC, and LRR regions of R3a using protein fold-recognition algorithms, as implemented in Phyre2 (Kelley and Sternberg 2009). Of the eight single-residue mutants described above, six result in amino acid substitutions in the LRR domain $\left(\mathrm{R}_{3} \mathrm{a}^{\mathrm{L} 668 \mathrm{P}}\right.$, R3 $\mathrm{a}^{\mathrm{K} 920 \mathrm{E}}, \mathrm{R} 3 \mathrm{a}^{\mathrm{E} 941 \mathrm{~K}}$, R3a $\mathrm{a}^{\mathrm{C} 950 \mathrm{R}}$, $\mathrm{R} \mathrm{a}^{\mathrm{E} 983 \mathrm{~K}}$, and $\mathrm{R} 3 \mathrm{a}^{\mathrm{K} 1250 \mathrm{R}}$ ), one in the $\mathrm{CC}$ domain $\left(\mathrm{R} 3 \mathrm{a}^{\mathrm{I} 148 \mathrm{~F}}\right)$, and one in the NB-ARC domain (R3a $\left.{ }^{\mathrm{N} 336 \mathrm{Y}}\right)$. We mapped the position of residues contained within the NB-ARC and LRR domains on the respective homology models we generated (Fig. 3B). Unfortunately, although we were able to generate a model for the R3a CC domain, it did not include the region containing the $\mathrm{I}^{148 \mathrm{~F}}$ mutant; therefore, it is not presented here. Such homology models can, typically, only be indicative of the position of individual amino acids. However, it is noteworthy that $\mathrm{R} 3 \mathrm{a}^{\mathrm{N} 336 \mathrm{Y}}$ maps near the $\mathrm{NB}$ site, at the junction of the $\mathrm{NB}$ and ARC1 regions, and close to the P-loop, sensor 1, GLPL, and MHD motifs that have previously been implicated in molecular switch events associated with nucleotide exchange in plant NB-LRR proteins (van Ooijen et al. 2008). The N336Y mutation places a bulky hydrophobic amino acid in place of a smaller residue and the resulting changes in the structure, due to steric constraints, may explain the observed phenotype. Although not included in a homology model, the effects of the $\mathrm{I}^{148 \mathrm{~F}}$ mutant may also be explained through the substitution of a larger residue in the place of a smaller one. The remaining six mutations $\left(\mathrm{R} 3 \mathrm{a}^{\mathrm{L} 668 \mathrm{P}}, \mathrm{R} 3 \mathrm{a}^{\mathrm{K} 920 \mathrm{E}}, \mathrm{R} 3 \mathrm{a}^{\mathrm{E} 941 \mathrm{~K}}, \mathrm{R} 3 \mathrm{a}^{\mathrm{C} 950 \mathrm{R}}, \mathrm{R} 3 \mathrm{a}^{\mathrm{E} 983 \mathrm{~K}}\right.$, and $\mathrm{R} 3 \mathrm{a}^{\mathrm{K} 1250 \mathrm{R}}$ ) are located in the LRR domain. Four of these mutations are clustered around LRR repeats 15 and 18 (Huang et al. 2005). The other mutations are distributed along and around the solenoid. Some of the mutations in the LRR domain are predicted to be in residues exposed on the protein surface and others buried in the hydrophobic core of the repeats.

\section{The $\mathrm{R3a}^{\mathrm{L}}{ }^{\mathrm{6} 8 \mathrm{P}}$ mutant shows increased response to $\mathrm{AVR} 3 \mathrm{a}^{\mathrm{KI}}$ compared with R3a.}

To determine whether the R3a+ single-residue mutants have altered sensitivity to AVR $3 \mathrm{a}^{\mathrm{KI}}$ compared with wild-type R3a, we co-infiltrated (side by side) $N$. benthamiana leaves with $A$. tumefaciens strains expressing mutant and wild-type R3a constructs mixed with different dilutions of A. tumefaciens strains expressing AVR $3 \mathrm{a}^{\mathrm{KI}}$. We then scored each pair for the combination giving the strongest HR (Fig. 4A; Supplementary Fig. S1). R3a ${ }^{\mathrm{L} 668 \mathrm{P}}$ consistently ( $>60 \%$ of infiltration sites) triggered a stronger $\mathrm{HR}$ than $\mathrm{R} 3 \mathrm{a}$ when co-infiltrated with $\mathrm{AVR} 3 \mathrm{a}^{\mathrm{KI}}$ whereas $\mathrm{R} 3 \mathrm{a}^{\mathrm{C} 950 \mathrm{R}}, \mathrm{R} 3 \mathrm{a}^{\mathrm{E} 983 \mathrm{~K}}$, and $\mathrm{R} 3 \mathrm{a}^{\mathrm{K} 1250 \mathrm{R}}$ occasionally (approximately $10 \%$ of infiltrations) triggered a stronger HR with AVR $3 \mathrm{a}^{\mathrm{KI}}$. We further confirmed that $\mathrm{R} 3 \mathrm{a}^{\mathrm{L} 668 \mathrm{P}}$ has an enhanced response to AVR $3 \mathrm{a}^{\mathrm{KI}}$ independently of the dilution level of the
A. tumefaciens strain carrying the effector (Fig. 4B). These findings indicate that this single-amino-acid change in R3a (L668P) not only expands the response of R3a to AVR3 $\mathrm{a}^{\mathrm{EM}}$ but also increases the sensitivity of R3a for its cognate effector AVR $3 \mathrm{a}^{\mathrm{KI}}$.

\section{R3a+ single-residue mutants respond to multiple variants of AVR3a.}

Although all the R3a+ mutants we identified have expanded response to AVR3a ${ }^{\mathrm{EM}}$, they may not have the same response spectrum to additional variants of AVR3a. To test whether the activity acquired by $\mathrm{R} 3 \mathrm{a}+$ resistance proteins extends to additional variants of AVR3a besides AVR $3 \mathrm{a}^{\mathrm{KI}}$ and AVR $3 \mathrm{a}^{\mathrm{EM}}$, we co-infiltrated the R3a+ single-residue mutants with a set of previously described AVR3a mutants (Bos et al. 2009). We selected AVR3a variants with Pro, Asp, Tyr, Phe, or Trp residues at position 80 (AVR3 $\mathrm{a}^{\mathrm{E} 80 \mathrm{X} / \mathrm{M} 103}$ ) because they do not trigger the HR when co-expressed with wild-type R3a in a wound-inoculation assay (Bos et al. 2009). Interestingly, the R3a+ singleresidue mutants showed variable response spectra to these AVR3a variants (Fig. 5; Supplementary Fig. S2). R3a ${ }^{\mathrm{E} 941 \mathrm{~K}}$ showed the widest spectrum, responding with an HR index of $>7.5$ to all tested AVR3a variants, followed by clones R3a $\mathrm{a}^{\mathrm{L} 668 \mathrm{P}}$, $\mathrm{R} 3 \mathrm{a}^{\mathrm{K} 920 \mathrm{E}}, \mathrm{R} 3 \mathrm{a}^{\mathrm{N} 336 \mathrm{Y}}$, and $\mathrm{R} 3 \mathrm{a}^{\mathrm{E} 983 \mathrm{~K}}$ (Fig. 5B). These results indicate that single-amino-acid changes in R3a can dramatically expand the response of this NB-LRR protein not only to AVR $3 \mathrm{a}^{\mathrm{EM}}$ but also to multiple artificial variants of AVR3a. The findings also show that the R3a mutants we recovered have variable response activities to AVR3a mutants.

\section{The $\mathrm{R3a}^{\mathrm{N} 336 \mathrm{Y}}$ mutant can respond}

to PcAVR3a4, an AVR3a homolog from $P$. capsici.

We hypothesized that some of the R3a+ mutants we identified may respond to members of the AVR3a family from another Phytophthora sp. To test this, we co-expressed the eight single-residue R3a+ mutants with several AVR3a-like effectors from the pepper and cucurbit pathogen P. capsici (Bos 2007). Remarkably, R3a ${ }^{\mathrm{N} 336 \mathrm{Y}}$, which carries an amino-acid substitution near the predicted NB pocket of R3a (Fig. 3B), consistently responded to the effector PcAVR3a4 (HR index approximately 6) whereas the wild-type R3a did not (HR index =0) (Fig. 6). $\mathrm{R} 3 \mathrm{a}^{\mathrm{I} 148 \mathrm{~F}}$, which is mutated in the $\mathrm{CC}$ domain and was previously tagged as an autoactive mutant (Fig. 3A), also responded to PcAVR3a4 (Fig. 6A). These results indicate that the singleamino-acid substitution N336Y can expand R3a response not only to AVR3a ${ }^{\mathrm{EM}}$ but also to another AVR3a family member from $P$. capsici.

\section{DISCUSSION}

The potato NB-LRR immune receptor R3a mediates resistance to strains of $P$. infestans that secrete the AVR $3 \mathrm{a}^{\mathrm{KI}}$ effector but not to strains that only produce the AVR $3 \mathrm{a}^{\mathrm{EM}}$ isoform. AVR $3 \mathrm{a}^{\mathrm{EM}}$ is the product of an Avr $3 a$ allele that is predominant in modern populations of $P$. infestans, meaning that $\mathrm{R} 3 \mathrm{a}$ is a "defeated" disease resistance gene in most potato production areas (Armstrong et al. 2005; Bos et al. 2009, 2010; Yoshida et al. 2013). In this study, we took the first steps to resurrect R3a by successfully screening and identifying R3a+ mutants that respond to both $\mathrm{AVR} 3 \mathrm{a}^{\mathrm{KI}}$ and $\mathrm{AVR} 3 \mathrm{a}^{\mathrm{EM}}$ (Figs. 1 and 2). In total, we identified eight single-amino-acid mutations that expanded R3a response to AVR $3 \mathrm{a}^{\mathrm{EM}}$, without compromising its activity toward AVR $3 \mathrm{a}^{\mathrm{KI}}$ (Fig. 3). The mutants span the length of the $\mathrm{R} 3 \mathrm{a}$ protein, providing unbiased and valuable insight into structure-function relationships in this immune receptor. $\mathrm{Re}$ markably, one of the R3a mutants, $\mathrm{R} 3 \mathrm{a}^{\mathrm{N} 336 \mathrm{Y}}$, gained the capacity to respond to an AVR3a homolog from another oomycete 


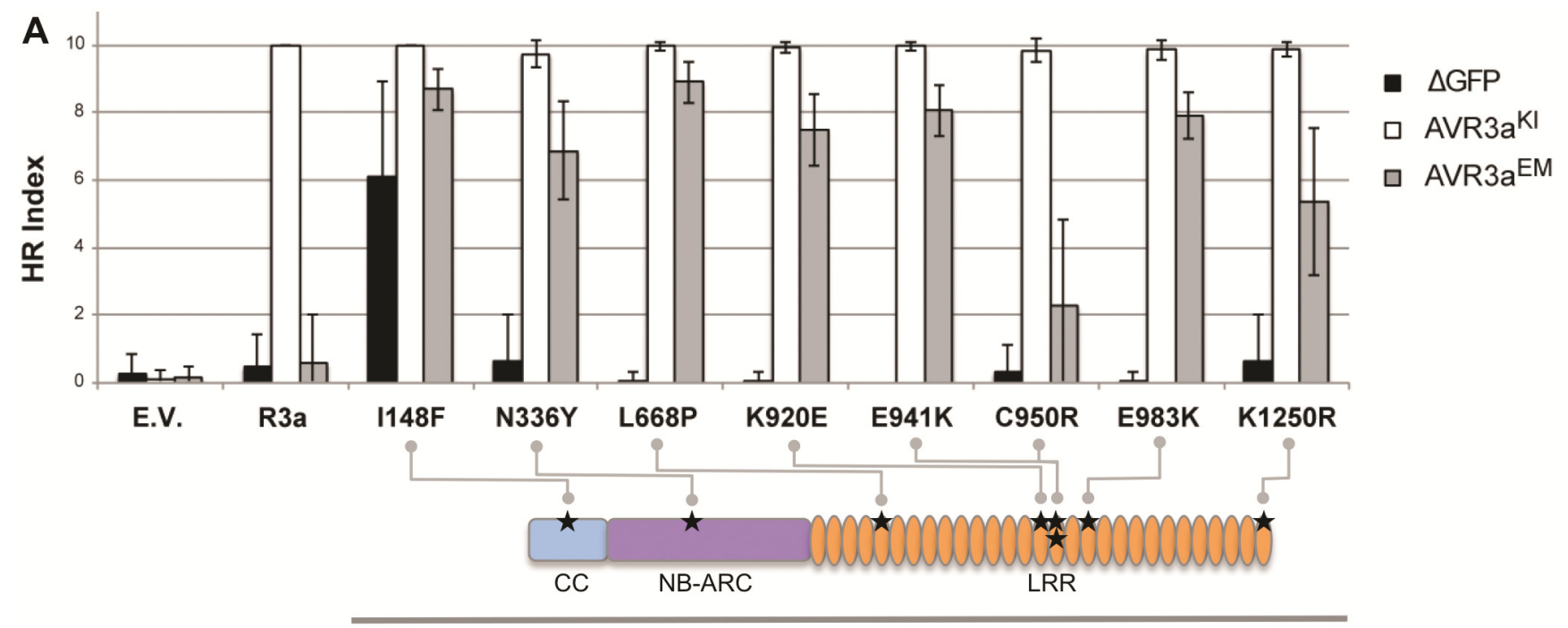

R3a+ clones

B

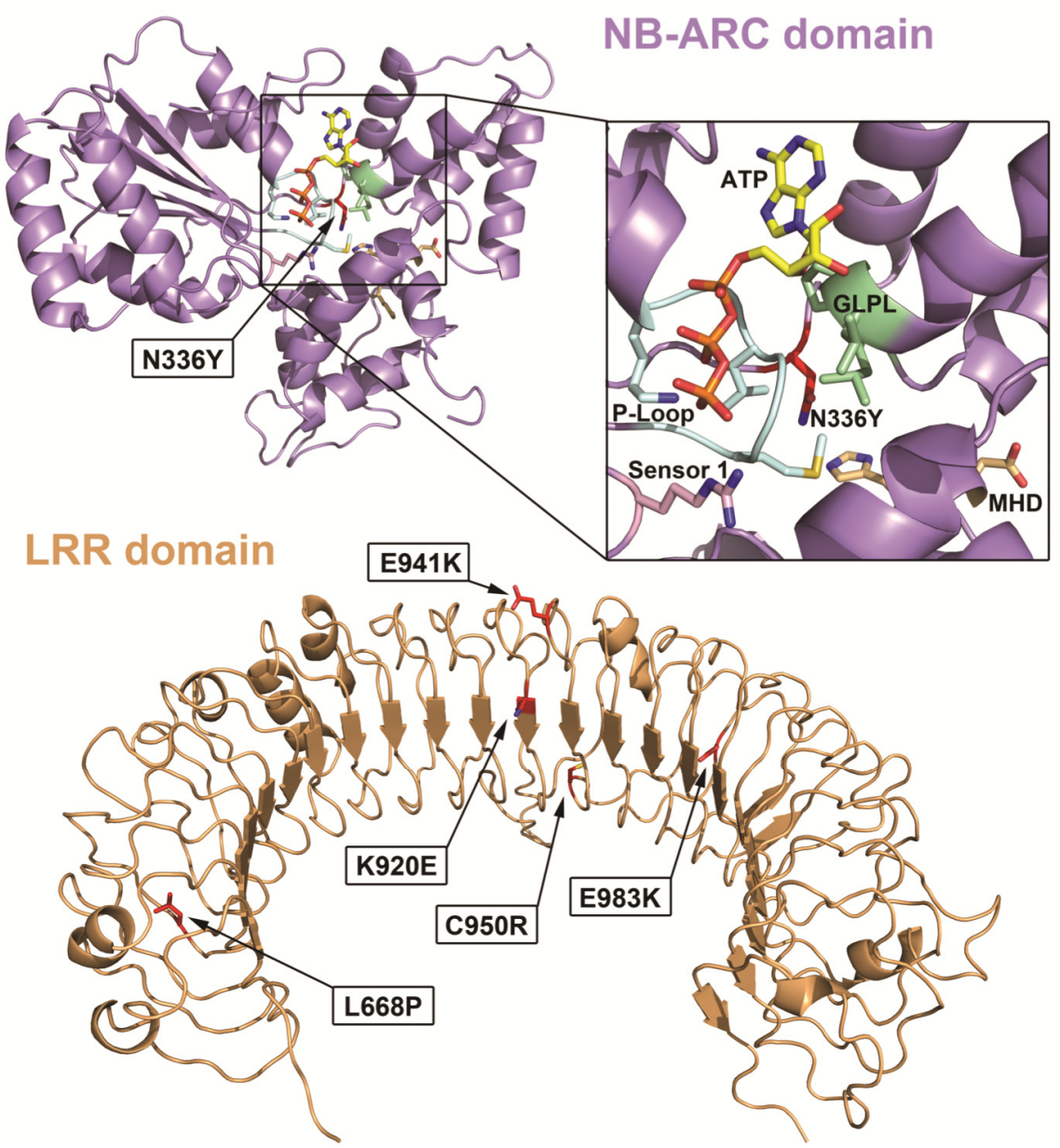

Fig. 3. Single amino acid changes located at different nucleotide-binding leucine-rich repeat-containing (NB-LRR) domains can expand R3a response to $\mathrm{AVR} 3 \mathrm{a}^{\mathrm{EM}}$. A, Single-residue mutation clones derived from the original R3a+ and wild-type R3a (all under transcriptional control of the Rpi-vnt1.1 promoter) were co-agroinfiltrated in Nicotiana benthamiana with AVR3 $\mathrm{a}^{\mathrm{EM}}, \mathrm{AVR} 3 \mathrm{a}^{\mathrm{KI}}$, or a truncated version of green fluorescent protein ( $\left.\triangle \mathrm{GFP}\right)$ expressed from a Potato virus $X$ (PVX)-based vector. The empty vector (E.V.) clone was included as control. Hypersensitive response index scored at 6 days postinfiltration (dpi) is plotted; bars represent the average of 13 to 18 replicas for $\triangle \mathrm{GFP}$ and AVR3a ${ }^{\mathrm{KI}}$ and 28 to 30 replicas for AVR $3 \mathrm{a}^{\mathrm{EM}}$; error bars represent standard deviation. B, Schematic (cartoon) representation of the homology models generated for the NB-ARC and LRR regions of the R3a protein. Models were generated using the Phyre2 server (Kelley and Sternberg 2009). The NB-ARC is shown in purple and the LRR in orange. The carbon atoms of the single-residue R3a+ mutations are shown in red and the carbon atoms of ATP are shown in yellow. The inset shows a close-up of the ADP/ATP binding site within the NBARC domain (here, carbon atoms are colored in cyan [P-loop], pink [sensor 1], green [GLPL motif], and orange [MHD motif]). Mutation K1250R is not shown because the region containing this residue was not modeled. 
species, the vegetable pathogen $P$. capsici. These results validate the strategy of Farnham and Baulcombe (2006) and Harris and colleagues (2013) in demonstrating that synthetic alleles of disease resistance genes with expanded specificity spectrum can be produced in the laboratory.

We screened a library of approximately 2,200 clones with $\mathrm{AVR}_{3} \mathrm{a}^{\mathrm{EM}}$ and recovered $17 \mathrm{R} 3 \mathrm{a}+$ clones (Figs. 1 and 2). This represents an approximately $0.8 \%$ success rate. Farnham and Baulcombe (2006) achieved a similar success rate because they recovered 13 gain-of-function mutants of $\mathrm{Rx}$ after screening 1,920 mutants (approximately $0.7 \%$ ). Given that our mutants have an average rate of nonsynonymous mutations of 4 and that R3a is 1,282 amino acids in length, the mutant library we generated had approximately $7 \times$ coverage for each amino acid $(2,200 \times 4 / 1,282=6.86)$. The depth of the screen is validated by the identification of a cluster of four mutations around LRR repeats 15 and 18 (Fig. 3B). However, because most mutant clones have multiple amino acid substitutions, we may have failed to recover mutants with compensating beneficial and detrimental mutations. Therefore, the screen, although successful, may have missed additional useful mutations. Nonetheless, the $7 \times$ deep R3a mutant library we constructed is a permanent resource that can be rescreened with additional forms of AVR3a from either P. infestans or other Phytophthora spp.

Two general mechanisms could underlie the ability of the R3a+ mutants to respond to additional Phytophthora effectors,
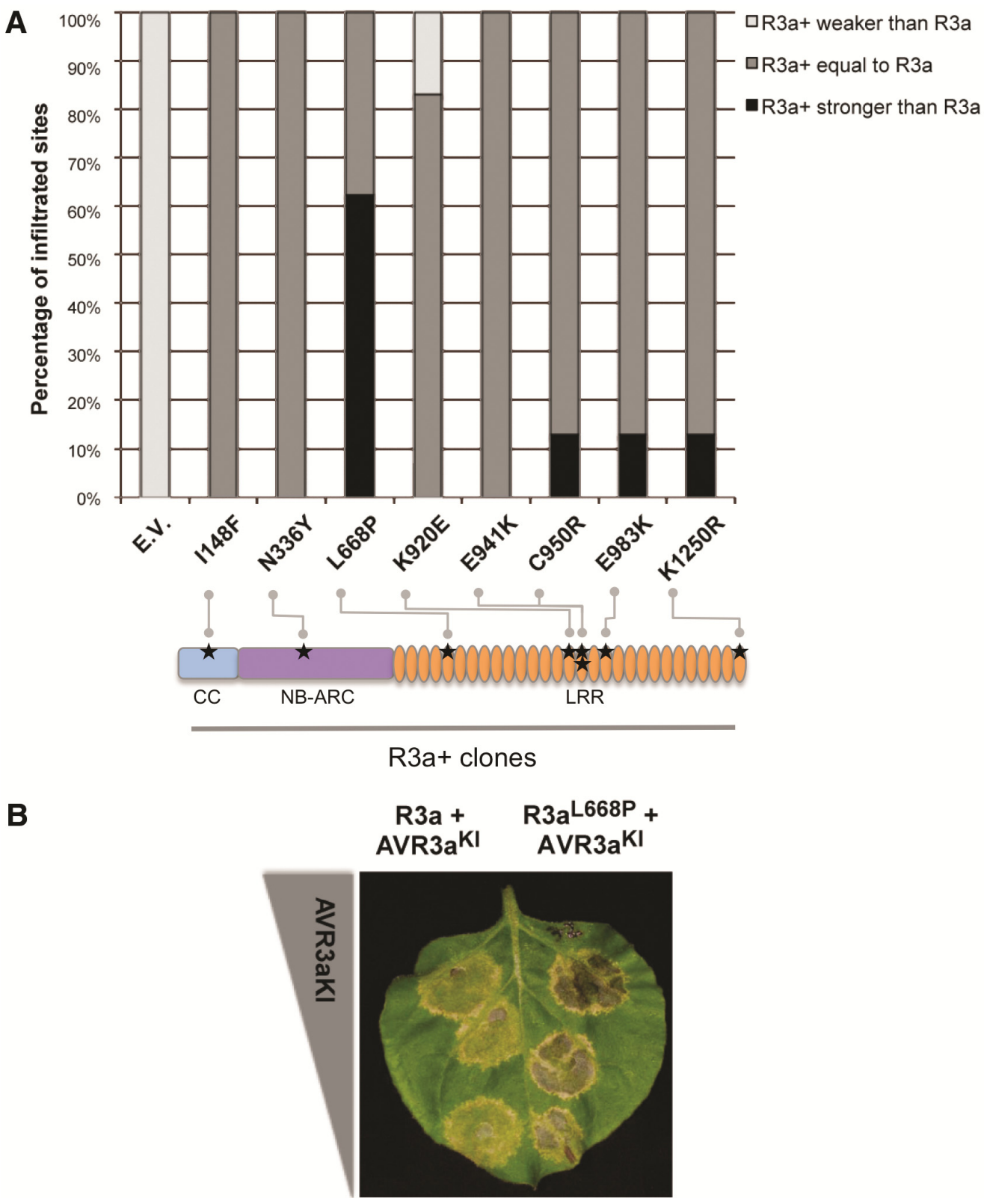

Fig. 4. The R3 $\mathrm{a}^{\mathrm{L} 668 \mathrm{P}}$ mutant shows increased response to $\mathrm{AVR} 3 \mathrm{a}^{\mathrm{KI}}$ compared with R3a. A, The single-residue mutant R3a+ clones or wild-type R3a (all under transcriptional control of the Rpi-vnt1.1 promoter; optical density at $600 \mathrm{~nm}\left[\mathrm{OD}_{600}\right]=0.3$ ) were co-agroinfiltrated side by side with serial dilutions of $\mathrm{AVR} 3 \mathrm{a}^{\mathrm{KI}}$ (under transcriptional control of the Cauliflower mosaic virus $35 \mathrm{~S}$ promoter) in Nicotiana benthamiana (from the tip to the base of the leaf, expressed in $\mathrm{OD}_{600}=0.04$ AVR3 $\mathrm{a}^{\mathrm{KI}}+0.11$ empty vector [E.V.], $0.075 \mathrm{AVR} 3 \mathrm{a}^{\mathrm{KI}}+0.075$ E.V., and $0.15 \mathrm{AVR} 3 \mathrm{a}^{\mathrm{KI}}$ ). The E.V. clone was included as control. Hypersensitive response was scored at 4 days postinfiltration (dpi) for neighbor spots (R3a+ and wild-type R3a in opposite sides of the leaf) as follows: "R3a+ stronger than R3a", "R3a+ equal to R3a", or "R3a+ weaker than R3a". Results for the lowest concentration of AVR3a ${ }^{\mathrm{KI}}$ are plotted as percentage of compared infiltrated areas showing each of the possible outcomes. B, A representative picture of an $N$. benthamiana leaf co-agroinfiltrated as explained in A with the R3a+ clone R3a ${ }^{\mathrm{L} 668 \mathrm{P}}$, and serial dilutions (upper = higher, inferior = lower) of Agrobacterium tumefaciens cells carrying the AVR3a ${ }^{\mathrm{KI}}$ construct (as detailed above). The picture was taken at $4 \mathrm{dpi}$. 


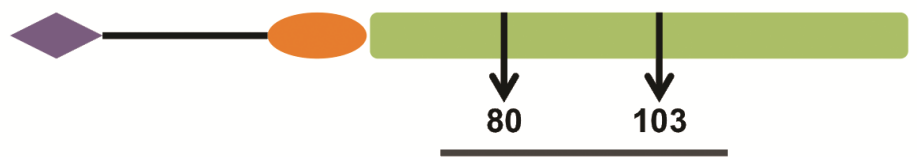

147 aa

\begin{tabular}{cc}
\hline$K$ & $I$ \\
\hline$E$ & $M$ \\
\hline$X$ & $M$ \\
\hline
\end{tabular}

AVR3a ${ }^{\mathrm{KI}}$

AVR3aEM

AVR3a ${ }^{\text {E80X/M103 }}$

B

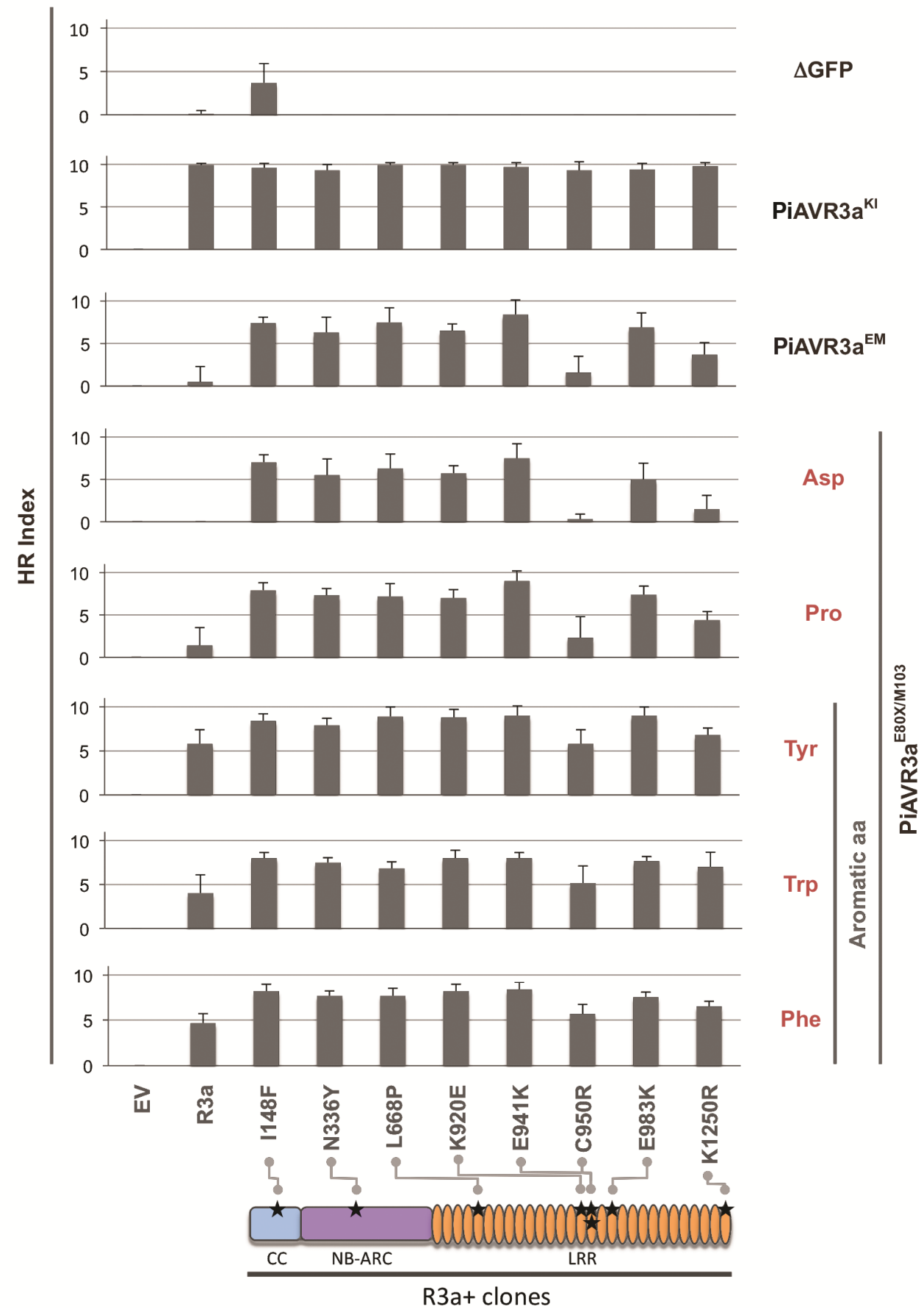

Fig. 5. R3a+ mutants respond to multiple AVR3a variants. A, Schematic representation of Phytophthora infestans effector protein AVR3a, showing polymorphic amino acid positions 80 and 103 in the effector domain. B, R3a+ single-residue mutants and wild-type R3a (all under transcriptional control of the Rpi-vnt1.1 promoter) were co-agroinfiltrated in Nicotiana benthamiana with a truncated version of green fluorescent protein ( $\Delta \mathrm{GFP})$, AVR3a ${ }^{\mathrm{KI}}$, $\mathrm{AVR}_{3} \mathrm{a}^{\mathrm{EM}}$, and a collection of AVR3a mutants with amino-acid substitutions (Pro, Asp, Tyr, Phe, or Trp) at position 80 in AVR3a ${ }^{\mathrm{E} 80 \mathrm{X} / \mathrm{M} 103}$. All these AVR3a variants were expressed from a Potato virus X (PVX)-based vector. The empty vector (E.V.) clone was included as control. Hypersensitive response (HR) index scored at 5 days postinfiltration (dpi) is plotted; columns represent the average of at least 12 replicas and error bars represent standard deviation. 
other than AVR3a ${ }^{\mathrm{KI}}$ (Harris et al. 2013; Lukasik and Takken 2009; Takken and Goverse 2012). The R3a+ mutants could be altered in recognition specificity, gaining the ability to sense a wider spectrum of effectors, either directly or indirectly. Alternatively, the R3a+ mutants could have increased activation sensitivity. Sensitized or "trigger-happy" mutants would have a lower threshold for activation, producing a stronger response to weak elicitors such as AVR3a ${ }^{\text {EM }}$ and PcAVR3a4 than wild- type R3a protein. According to current knowledge on structure-function relationships of NB-LRR proteins, mutations in the C-terminal half of the LRR domain are expected to affect recognition specificity, whereas those located in the $\mathrm{CC}$, NBARC, and N-terminal region of the LRR domain are more likely to affect activation and signaling threshold (Takken and Goverse 2012). Therefore, the eight R3a+ amino-acid mutations may affect different aspects of the response to AVR3a

A

$\triangle G F P$

AVR3aKI

AVR3a ${ }^{\mathrm{EM}}$

PcAVR3a4

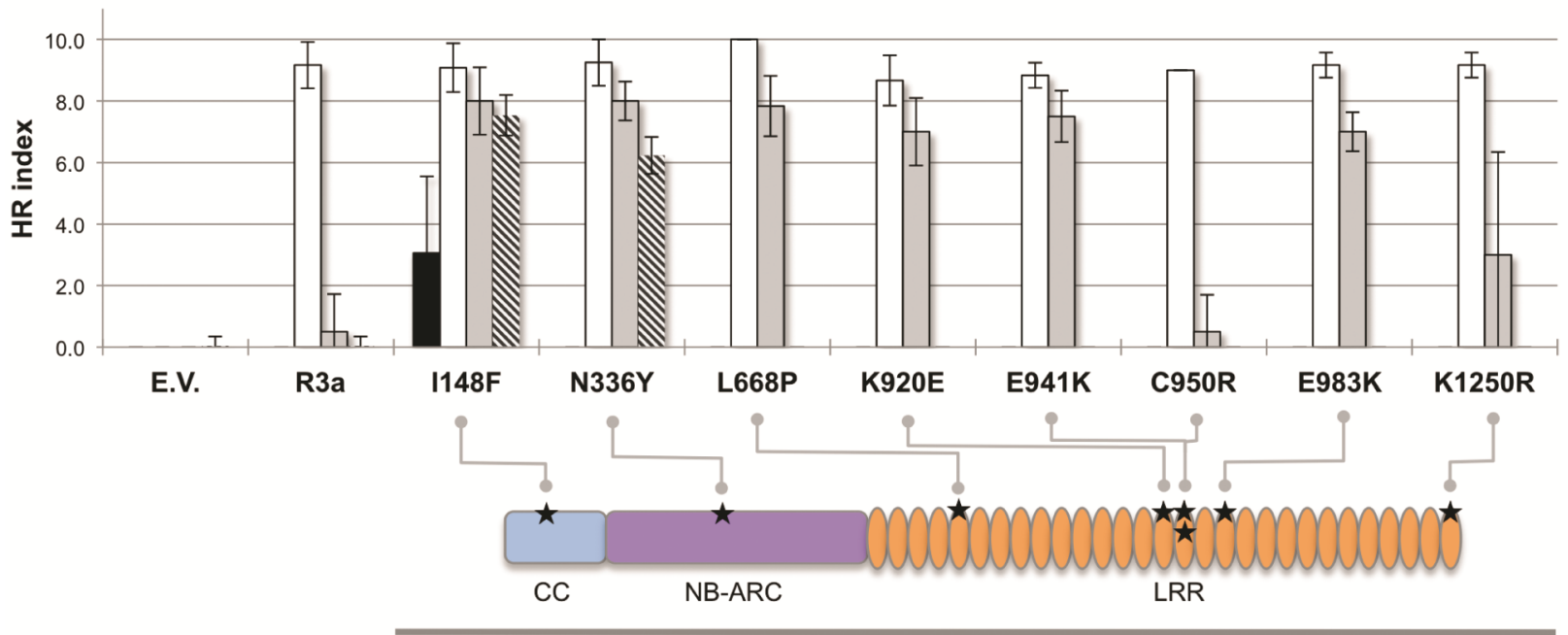

$\mathrm{R} 3 \mathrm{a}+$ clones

B

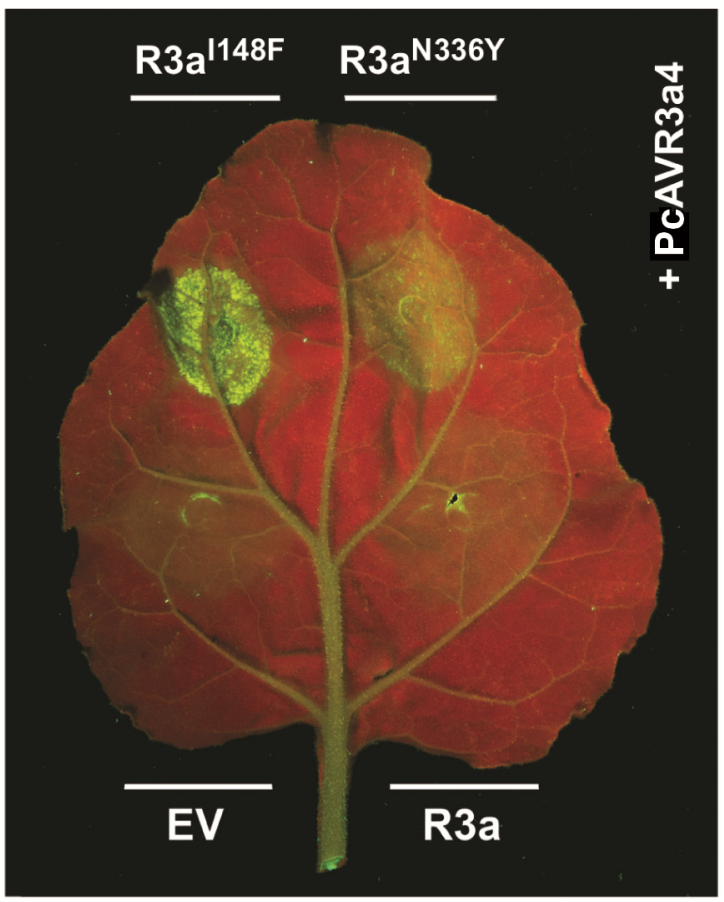

Fig. 6. The R3a ${ }^{\mathrm{N} 336 \mathrm{Y}}$ mutant responds to PcAVR3a4, an AVR3a homolog from the vegetable pathogen Phytophthora capsici. A, The R3a+ single-residue mutants and wild-type R3a (all under transcriptional control of the Rpi-vnt1.1 promoter) were co-agroinfiltrated in Nicotiana benthamiana with a truncated version of green fluorescent protein $(\triangle \mathrm{GFP}), \mathrm{AVR} 3 \mathrm{a}^{\mathrm{KI}}, \mathrm{AVR} 3 \mathrm{a}^{\mathrm{EM}}$, and the AVR3a family member from P. capsici, PcAVR3a4. All these effectors were expressed from a Potato virus X (PVX)-based vector. The empty vector (E.V.) clone was included as control. Hypersensitive response index scored at 5 days postinfiltration (dpi) is plotted; columns represent the average of at least 10 replicas and error bars represent standard deviation. B, A representative picture of an N. benthamiana leaf co-agroinfiltrated as explained in A, with PcAVR3a4 in combination with E.V., wild-type R3a, or the R3a+ clones R3a ${ }^{1148 F}$ and $\mathrm{R} 3 \mathrm{a}^{\mathrm{N} 336 \mathrm{Y}}$. The picture was taken at 5 dpi. 
effectors given that they are spread along the R3a protein (Fig. 3 ), with $\mathrm{R} 3 \mathrm{a}^{\mathrm{I} 148 \mathrm{~F}}, \mathrm{R} 3 \mathrm{a}^{\mathrm{N} 336 \mathrm{Y}}$, and $\mathrm{R} 3 \mathrm{a}^{\mathrm{L} 668 \mathrm{P}}$ corresponding to regions possibly involved in signal transduction and $\mathrm{R} 3 \mathrm{a}^{\mathrm{K} 920 \mathrm{E}}$, $\mathrm{R} 3 \mathrm{a}^{\mathrm{E} 941 \mathrm{~K}}$, R3a $\mathrm{a}^{\mathrm{C} 950 \mathrm{R}}, \mathrm{R} 3 \mathrm{a}^{\mathrm{E} 983 \mathrm{~K}}$, and $\mathrm{R} 3 \mathrm{a}^{\mathrm{K} 1250 \mathrm{R}}$ located in the region of the protein that might influence specificity.

Four of the eight amino-acid substitutions that enhance the response to AVR $3 \mathrm{a}^{\mathrm{EM}}$ map to the central region of the LRR domain (repeats 15 to 18 ) (Fig. 3), pointing to a potential hotspot. Of these mutations, C950R is phenotypically distinct, conferring a relatively weak response to AVR $3 \mathrm{a}^{\mathrm{EM}}$ and other AVR3a variants (Figs. 3A and 5B). The three remaining mutants (K920E, E941K, and E983K) are phenotypically similar in all the assays we tested. All three mutants carry substitutions in charged amino acids that resulted in a switch from a positively to a negatively charged residue, or vice-versa. These changes are consistent with an altered binding state of the R3a protein to a ligand that could be either the effector or a plant protein. Interestingly, LRR 15 to 18 exactly match the region identified by van Ooijen and colleagues (2010) as the binding site of I-2, an R3a homolog from tomato, to the small heat shock protein 20 RSI2. These authors showed that RSI2 is required for I-2 function, possibly by affecting stabilization of this NB-LRR protein. Therefore, mutations in this central region of the LRR domain could alter binding to a plant chaperone protein such as RSI2, therefore perturbing steady-state levels of R3a. Alternatively, the central region of the LRR domain could be the binding site to the AVR3a effector or a protein complex between the effector and host proteins.

The L668P mutation in the fifth LRR is the only one of the eight mutations that resulted in significantly increased response to $\mathrm{AVR} 3 \mathrm{a}^{\mathrm{KI}}$, and appears to act by sensitizing the R3a protein (Fig. 4). This finding confirms previous observations implicating the $\mathrm{N}$ terminus of the LRR domain in signaling (Bendahmane et al. 2002; Farnham and Baulcombe 2006; Takken and Goverse 2012). The N-terminal region of the LRR domain is thought to fold onto the NB-ARC domain to stabilize the NBLRR protein, maintaining it in an autoinhibited state (Takken and Goverse 2012). The Pro at position 668 may perturb the conformation of the $\mathrm{N}$ terminus of the LRR domain, resulting in altered intramolecular interaction with the NB-ARC domain. Importantly, the R3 $\mathrm{a}^{\mathrm{L} 668 \mathrm{P}}$ mutant is not autoactive (Figs. 3A, $5 \mathrm{~B}$, and $6 \mathrm{~A}$ ). Therefore, mutants in the $\mathrm{N}$ terminus of the LRR domain can be used to optimize NB-LRR protein activity and modulate the response to both weakly and strongly recognized effectors. Such mutants could be useful for enhancing the response of an NB-LRR receptor to a pathogen effector without the negative effects of effector-independent activation.

The NB-ARC domain mutation N336Y was the only one that resulted in a gain of response to an AVR3a-like effector from a different Phytophthora sp., without triggering autoactivity (Fig. 6). This finding is reminiscent of the results of Farnham and Baulcombe (2006), which showed that single-residue LRR mutants of the Rx protein (mutants M1 to M4) respond to the coat protein $(\mathrm{CP})$ of a new virus, PopMV. Farnham and Baulcombe (2006) concluded that Rx mutants M1 to M4 gained recognition of the PopMV CP. Subsequently, Harris and colleagues (2013) showed that the RxM1 mutant can be enhanced by sensitizing mutations in the NB-ARC domain, and that without M1 these sensitized mutants ( $\mathrm{xxS} 1$ to $\mathrm{RxS} 4)$ do not produce a robust response to PopMV CP. In our case, a single mutation in the NB-ARC domain of R3a was sufficient to confer a substantial response to the $P$. capsici effector PcAVR3a4 (Fig. 6). Although, phenotypically, the $\mathrm{R}^{3} \mathrm{a}^{\mathrm{N} 336 \mathrm{Y}}$ mutant seems to be similar to the M1 to M4 mutations, it seems unlikely that a mutation near the NB site would affect recognition per se. Perhaps $\mathrm{R} 3 \mathrm{a}^{\mathrm{N} 336 \mathrm{Y}}$ is an oversensitized mutant that reveals cryptic activities of $\mathrm{R} 3 \mathrm{a}$. If correct, this model implies that immune receptors like R3a have a much greater capacity to recognize diverse pathogen effectors than previously thought. Mutations similar to N336Y have the potential to reveal cryptic activities of immune receptors with potentially important implications for agriculture. In addition, the unexpected gain-of-function conferred by the N336Y mutation highlights the value of mutagenizing full-length NB-LRR proteins without preconceived assumptions about the LRR being a recognition domain (Farnham and Baulcombe 2006).

This work has implications for crop improvements. However, preliminary infection assays, conducted after transient and stable expression of the R3a+ mutants described here, failed to detect increased resistance to $P$. infestans in either $N$. benthamiana or potato plants. The response of the R3a+ clones to AVR $3 \mathrm{a}^{\mathrm{EM}}$ is variable in strength (Fig. 3A) but, in general, it remains weaker than the response to AVR $3 \mathrm{a}^{\mathrm{KI}}$. Assaying different residues in each of the $\mathrm{R} 3 \mathrm{a}+$ mutant positions or combining mutations in the same R3a+ clone could help to optimize the strength of the response to AVR $3 \mathrm{a}^{\mathrm{EM}}$. In particular, this last approach proved to be valid for Rx NB-LRR, because combination of mutations in different domains led to a more robust response (Harris et al. 2013). Combination of two or more single-amino-acid changes identified in R3a+ clones may be required to assemble a more stable recognition complex in order to elicit resistance. Screening for the appearance of the HR has proven to be successful in selecting for NB-LRR clones that confer resistance to pathogens (Farnham and Baulcombe 2006). Nevertheless, in some instances, host-programmed cell death can be uncoupled from resistance (Century et al. 1995; Hao et al. 2013; Heidrich et al. 2012), and we cannot ignore the possibility that the cell death response triggered by the R3a+ mutants in the presence of AVR $3 \mathrm{a}^{\mathrm{EM}}$ may take place in an inadequate spatiotemporal frame that compromises resistance. In addition, it is unclear whether the recognition of AVR3a by $\mathrm{R} 3 \mathrm{a}$ is direct or dependent on host-specific proteins (guardee, decoy, or co-factor proteins) (Bos et al. 2009; Engelhardt et al. 2012). To date, yeast two-hybrid and co-immunoprecipitation experiments have failed to show a direct interaction between AVR3a and R3a (Engelhardt et al. 2012). Clearly, a better understanding of how R3a functions is required to translate the gain of effector response noted in the $\mathrm{R} 3 \mathrm{a}+$ mutants into pathogen disease resistance.

The ability to extend the response of an NB-LRR protein to a wider range of related effectors offers the opportunity to develop broad-spectrum solutions to plant pathogens. In the case of the AVR3a family, multiple members exist in phylogenetically diverse Phytophthora spp. (Haas et al. 2009; Tyler et al. 2006). As Phytophthora genome sequences become available, it will be possible to identify AVR3a-like proteins and screen them with the R3a mutant library. Artificial evolution by random mutagenesis complements site-directed mutagenesis and domain shuffling approaches to improve NB-LRR proteins (Steinbrenner et al. 2012; Stirnweis et al. 2013; Takken and Goverse 2012). In the future, combining these different approaches could be used to generate synthetic $R$ genes with novel beneficial properties. In addition, with the advent of plant genome editing, such beneficial mutations may be introduced into an elite crop cultivar genome without the insertion of additional sequences (Belhaj et al. 2013; Li et al. 2013; Mussolino and Cathomen 2013; Nekrasov et al. 2013; Schornack et al. 2013; Shan et al. 2013).

\section{MATERIALS AND METHODS}

\section{Microbial strains and growth conditions.}

A. tumefaciens GV3101 (Hellens et al. 2000) was used in molecular cloning experiments and library construction, and was 
routinely cultured at $28^{\circ} \mathrm{C}$ in Luria-Bertani (LB) media using appropriate antibiotics (Sambrook and Russell 2001). All bacterial DNA transformations were conducted by electroporation using standard protocols (Sambrook and Russell 2001).

\section{R3a mutant library.}

Random mutagenesis of the full-length $R 3 a$ coding sequence was performed using the Diversify PCR random mutagenesis kit from Clontech (Takara Bio Company, Mountain View, CA, U.S.A.). PCR amplification was performed using S. demissum $R 3 a$ gene as template (Huang et al. 2005), following the provider's protocol. Primers were designed to amplify the $R 3 a$ coding sequence, including restriction enzymes recognition sites for subcloning (R3a_BamHI_Fw: 5'-GGAGGATCCAT GGAGATTGGCTTAGCAG-3' and R3a_SpeI_Rev: 5'-GGA ACTAGTTCACATGCATTCCCTATC-3'). Different conditions were tested to generate various mutation rates. Conditions that gave a mutation rate of one to two mutations every $1,000 \mathrm{bp}$ (four to eight in a 4,000-bp gene) were selected. The PCR reaction was purified using a QIAquick PCR purification kit (Qiagen, Hilden, Germany). The purified PCR product and the binary vector pCB302-3 (Xiang et al. 1999) were digested with BamHI and SpeI restriction enzymes (Roche Applied Science, Penzberg, Germany). The digested PCR products and vector were gel-purified using the kit Wizard SV Gel and PCR cleanup system (Promega Corp., Madison, WI, U.S.A.), and ligation mixes were directly transformed into A. tumefaciens GV3101 by electroporation. Transformants were picked into 384-well plates using a QPix colony-picking robot (Genetix, New Milton, U.K.) for preparation of freezer stocks. The library was kept at $-80^{\circ} \mathrm{C}$.

\section{R3a mutant library screening.}

The screening was performed by agroinfiltration transient assays in N. benthamiana (Bos et al. 2006, 2009; Van der Hoorn et al. 2000). In all, 2.0-ml 96 Deepwell plates (StarLab, Hamburg, Germany) containing $500 \mu \mathrm{l}$ of LB media with antibiotics (rifampicin at $50 \mathrm{mg} / \mathrm{liter}$, gentamicin at $20 \mathrm{mg} / \mathrm{liter}$, and kanamycin at $50 \mathrm{mg} / \mathrm{liter}$ ) were inoculated with the library clones and grew at $28^{\circ} \mathrm{C}$ for $48 \mathrm{~h}$ (to reach an optical density at $600 \mathrm{~nm}\left[\mathrm{OD}_{600}\right]$ of 1 to 1.2). Cultures were pelleted by centrifugation $\left(5 \mathrm{~min}\right.$ at $3,500 \mathrm{rpm}$ and $15^{\circ} \mathrm{C}$ ) and resuspended with infiltration buffer $(0.5 \%$ MS salts, $10 \mathrm{mM}$ MES, $2 \%$ sucrose, and $200 \mu \mathrm{M}$ acetosyringone, $\mathrm{pH}$ 5.6) to a final $\mathrm{OD}_{600}$ of 0.6. A. tumefaciens GV3101 transformed with pGR106-FLAGAVR3a_K ${ }^{80} \mathrm{I}^{103}\left(\mathrm{AVR} 3 \mathrm{a}^{\mathrm{KI}}\right.$ ) and pGR106-FLAG-AVR3a_E ${ }^{80} \mathrm{M}^{103}$ $\left(\right.$ AVR3 $\mathrm{a}^{\mathrm{EM}}$ ) (Armstrong et al. 2005; Bos et al. 2006; Lu et al. 2003) were grown for agroinfiltration as previously described (Van der Hoorn et al. 2000), except that LB media supplemented with rifampicin at $50 \mathrm{mg} / \mathrm{liter}$, gentamicin at $20 \mathrm{mg} / \mathrm{liter}$, and kanamycin at $50 \mathrm{mg} / \mathrm{liter}$ was used. Cultures were pelleted and resuspended in infiltration buffer as described above. For transient co-expression of R3a, R3a mutant clones, and AVR3a, the cells resuspended in infiltration buffer were mixed to have a final $\mathrm{OD}_{600}=0.3$ (R3a clones) and 0.15 (AVR3a clones). $A$. tumefaciens GV3101 transformed with pGR106- $\Delta$ GFP (containing a truncated version of $g f p$ as described by Bos and colleagues [2006]) was grown as the AVR3a clones. Agroinfiltration experiments were performed on 4-week-old $N$. benthamiana plants. Plants were grown and maintained throughout the experiments in a controlled environment room with a temperature of 22 to $25^{\circ} \mathrm{C}$ and high light intensity. HR phenotype development was monitored from 3 to $8 \mathrm{dpi}$.

\section{Agroinfiltration assays.}

Selected R3a+ clones were co-agroinfiltrated in $N$. benthamiana leaves to compare their relative response to different effec- tor proteins. Agroinfiltration was performed as detailed above. Each combination of wild-type R3a or R3a+ and effector protein (or $\triangle \mathrm{GFP}$ ) was infiltrated as 10 to 12 replicates. HR phenotype was scored daily up to $7 \mathrm{dpi}$, according to an arbitrary scale from 0 (no HR phenotype observed) to 10 (confluent necrosis). In all the agroinfiltration experiments (except for the experiment corresponding to Figure 4), pGR106-AVR $3 \mathrm{a}^{\mathrm{KI}}$, pGR106-AVR3a ${ }^{\mathrm{EM}}$, pGR106-AVR3a ${ }^{\mathrm{E} 80 \mathrm{X} / \mathrm{M} 103}$ (amino acids 23 to 147), or pGR106-PcAVR3a4 (amino acids 22 to 122) constructs were used to express AVR3a or PcAVR3a mature proteins (without signal peptide) (Armstrong et al. 2005; Bos 2007; Bos et al. 2006, 2009). All these constructs were delivered using A. tumefaciens GV3101. In agroinfiltration experiments (Fig. 4), AVR3a $\mathrm{a}^{\mathrm{KI}}$ (without signal peptide) was expressed from a pK7WGF2 based binary vector (Karimi et al. 2002; Rietman et al. 2012).

\section{Sequence analyses.}

Plasmid DNA from the 17 candidate clones $(\mathrm{R} 3 \mathrm{a}+)$ was isolated and R3a inserts were sequenced by Macrogen Sequencing Service (Seoul, Korea) using several primers to allow full coverage. Base-calling and quality values were obtained using the Phred algorithm (Ewing and Green 1998). Sequences were analyzed using Sequencher 4.1 (Genes Code Corp, Ann Arbor, MI, U.S.A.).

\section{Targeted mutagenesis of R3a.}

$\mathrm{R} 3 \mathrm{a}+$ clones with single residue mutations were obtained by GenScript Site-Directed Mutagenesis Service (Piscataway, NJ, U.S.A.). We selected $>20$ single residues from the long list of mutations to cover the R3a+ mutants that gave the most robust phenotypes. The binary vector pCBNptII-vnt1.1P/T-R3a was used as template and destination for the mutagenized R3a sequences. This binary vector was assembled using the pCBNptII binary vector backbone, modified in order to clone $R 3 a$ (wild-type or mutagenized sequences) under the transcriptional control of the Rpi-vnt1.1 promoter and terminator sequences (Foster et al. 2009; Pel et al. 2009). The pCBNptII binary vector was constructed as follows: a fragment containing nptII coding sequence and nos promoter and terminator regulatory elements was obtained by digesting the pBINPlus binary vector (van Engelen et al. 1995) with the restriction enzymes HindIII and EcoRI (Roche Applied Science). The NptII-containing cassette was ligated to the pCB302-3 binary vector (Xiang et al. 1999) previously digested with HindIII and EcoRI. The recombinant plasmid (pCBNptII) was digested with SmaI and $X b a \mathrm{I}$ (Roche Applied Science), and blunt ends were generated using the Klenow fragment of Escherichia coli DNA polymerase I (New England Biolabs, Ipswich, MA, U.S.A.) followed by dephosphorilation with the shrimp alkaline phosphatase (Promega). Rpivnt1.1 promoter and terminator sequences were amplified by overlapping PCR using primers designed to introduce convenient restriction enzyme recognition sequences: Rvnt1.1P_Sma_Fw (5'-GAACCCGGGAGTT ATACACCCTACATTCTACTC-3'), Rvnt1.1T_SacI_Rev (5'GAATTGAGCTCCTTTGAAAAGAGGCTTCATACTC- ${ }^{\prime}{ }^{\prime}$ ), Rvnt1.1P_overlap_Rev (5'-CTGTGATATTCGTAAACACAAT AAGGATCCTTTTGTTAGCTG-3'), and Rvnt1.1T overlap_Fw (5'-CTTATTGTGTTTACGAATATCACAGGTTCTAG AAATAATTATTTACG-3'). PCR was performed using, as template, a pGEM-T Easy plasmid containing $S$. venturii Rpivnt1.1 sequence (Foster et al. 2009), and the amplification product was phosphorylated with T4 polynucleotide kinase (New England Biolabs) for ligation into the pCBNptII binary plasmid prepared as described above. The recombinant plasmid was named pCBNptII-vnt1.1P/T. $R 3 a$ was amplified by PCR using pCB302-3_R3a as template, and the following primers: R3a- 
BamHI-Fw (5'-GGAGGATCCACCATGGAGATTGGCTTAG CAGTTGGTG-3') and PCB302_3Rv (5'-ACATGCTTAACGT AATTCAACAG-3'). The PCR amplification product was digested with $B a m \mathrm{HI}$ and $\mathrm{XbaI}$ restriction enzymes, gel purified, and ligated into pCBNptII-vnt1.1P/T previously treated with the same restriction enzymes.

\section{R3a structure predictions.}

Homology models of the individual CC, NB-ARC, and LRR regions of $\mathrm{R} 3 \mathrm{a}$ were generated using protein fold recognition algorithms, as implemented in Phyre2 (Kelley and Sternberg 2009), and sequences covering the individual domains. Phyre 2 revealed the highest score for the $\mathrm{CC}$ domain using the $\mathrm{CC}$ region of MLA10 as a template (PDB file 3QFL, confidence $99.7 \%$, sequence identity $15 \%$ ). However, this model only covered the region between amino acid 14 and 131 and did not show the position of $\mathrm{I}^{148}$. Searches with the sequence of the NB-ARC region showed the highest modeling score using CED4 as a template, and this generated a model spanning residues 181 to 515 (PDB file 2A5Y, confidence 100\%, sequence identity $16 \%$ ). The template used for the LRR region was the toll-like receptor 3 ligand-binding domain (PDB file 2A0Z, confidence $100 \%$, sequence identity $14 \%$ ). Because the resulting model covers residues 584 to 1,206 , mutation K1250R is not shown in Figure 3B. Note that the LRR repeat numbering is based on Huang and colleagues (2005).

\section{ACKNOWLEDGMENTS}

This work was supported by the European Research Council (ERC, proposal NGRB), the U.K. Biotechnology and Biological Sciences Research Council (BBSRC grants BB/J004553/1 and BB/I019557/1), the Gatsby Charitable Foundation, and the John Innes Foundation. M. E. Segretin was supported by the Consejo Nacional de Investigaciones Científicas y Técnicas (CONICET). The funders had no role in study design, data collection and analysis, decision to publish, or preparation of the manuscript. We thank A. Giannakopoulou, S. Schornack, N. Champouret, B. Staskawicz, E. Huitema, S. Huang, V. Vleeshouwers, I. Hein, and P. Birch for useful discussions or for providing biomaterial; K. Kowitwanich for technical support; G. Bennett for technical advice; and A. Bennaceur for promoting our collaborative interactions. M. E. Segretin, M. Pais, M. Franceschetti, A. Chaparro-Garcia, M. J. Banfield and S. Kamoun conceived and designed the experiments. M. E. Segretin, M. Pais, M. Franceschetti, A. Chaparro-Garcia, and J. I. B. Bos performed the experiments. M. E. Segretin, M. Pais, M. Franceschetti, M. J. Banfield and S. Kamoun analyzed the data. M. E. Segretin, M. Pais, M. Franceschetti, M. J. Banfield and S. Kamoun wrote the paper.

\section{LITERATURE CITED}

Armstrong, M. R., Whisson, S. C., Pritch: ard, L., Bos, J. I., Venter, E., Avrova, A. O., Rehmany, A. P., Bohme, U., Brooks, K., Cherevach, I., Hamlin, N., White, B., Fraser, A., Lord, A., Quail, M. A., Churcher, C., Hall, N., Berriman, M., Huang, S., Kamoun, S., Beynon, J. L., and Birch, P. R. 2005. An ancestral oomycete locus contains late blight avirulence gene Avr3a, encoding a protein that is recognized in the host cytoplasm. Proc. Natl. Acad. Sci. U.S.A. 102:7766-7771.

Belhaj, K., Chaparro-Garcia, A., Kamoun, S., and Nekrasov, V. 2013. Plant genome editing made easy: Targeted mutagenesis in model and crop plants using the CRISPR/Cas system. Plant Methods 9:39.

Bendahmane, A., Farnham, G., Moffett, P., and Baulcombe, D. C. 2002. Constitutive gain-of-function mutants in a nucleotide binding siteleucine rich repeat protein encoded at the Rx locus of potato. Plant J. 32:195-204

Bernoux, M., Ve, T., Williams, S., Warren, C., Hatters, D., Valkov, E., Zhang, X., Ellis, J. G., Kobe, B., and Dodds, P. N. 2011. Structural and functional analysis of a plant resistance protein TIR domain reveals interfaces for self-association, signaling, and autoregulation. Cell Host Microbe 9:200-211.

Birch, P. R. J., Boevink, P. C., Gilroy, E. M., Hein, I., Pritchard, L., and Whisson, S. C. 2008. Oomycete RXLR effectors: Delivery, functional redundancy and durable disease resistance. Curr. Opin. Plant Biol. $11: 373-379$
Bos, J. I. B. 2007. Function, Structure and Evolution of the RXLR Effector AVR3a of Phytophthora infestans. The Ohio State University, Columbus, OH, U.S.A.

Bos, J. I. B., Kanneganti, T. D., Young, C., Cakir, C., Huitema, E., Win, J., Armstrong, M. R., Birch, P. R., and Kamoun, S. 2006. The C-terminal half of Phytophthora infestans RXLR effector AVR3a is sufficient to trigger R3a-mediated hypersensitivity and suppress INF1-induced cell death in Nicotiana benthamiana. Plant J. 48:165-176.

Bos, J. I. B., Chaparro-Garcia, A., Quesada-Ocampo, L. M., McSpadden Gardener, B. B., and Kamoun, S. 2009. Distinct amino acids of the Phytophthora infestans effector AVR3a condition activation of R3a hypersensitivity and suppression of cell death. Mol. Plant-Microbe Interact. 22:269-281.

Bos, J. I. B., Armstrong, M. R., Gilroy, E. M., Boevink, P. C., Hein, I., Taylor, R. M., Zhendong, T., Engelhardt, S., Vetukuri, R. R., Harrower, B., Dixelius, C., Bryan, G., Sadanandom, A., Whisson, S. C., Kamoun, S., and Birch, P. R. 2010. Phytophthora infestans effector AVR3a is essential for virulence and manipulates plant immunity by stabilizing host E3 ligase CMPG1. Proc. Natl. Acad. Sci. U.S.A. 107:9909-9914.

Boutemy, L. S., King, S. R., Win, J., Hughes, R. K., Clarke, T. A., Blumenschein, T. M., Kamoun, S., and Banfield, M. J. 2011. Structures of Phytophthora RXLR effector proteins: A conserved but adaptable fold underpins functional diversity. J. Biol. Chem. 286:35834-35842.

Bozkurt, T. O., Schornack, S., Banfield, M. J., and Kamoun, S. 2012. Oomycetes, effectors, and all that jazz. Curr. Opin. Plant Biol. 15:483-492.

Cavalier-Smith, T., and Chao, E. E. 2006. Phylogeny and megasystematics of phagotrophic heterokonts (kingdom Chromista). J. Mol. Evol. 62:388-420.

Century, K. S., Holub, E. B., and Staskawicz, B. J. 1995. NDR1, a locus of Arabidopsis thaliana that is required for disease resistance to both a bacterial and a fungal pathogen. Proc. Natl. Acad. Sci. U.S.A. 92:65976601.

Cooke, D. E. L. and Andersson, B. 2013. Phytophthora infestans and potato late blight in Europe. Pages 59-67 in: Phytophthora: A Global Perspective (CABI Plant Protection Series). K. Lamour, ed. CAB International, Oxon, U.K.

Dodds, P. N., and Rathjen, J. P. 2010. Plant immunity: Towards an integrated view of plant-pathogen interactions. Nat. Rev. Genet. 11:539548.

Dodds, P. N., Lawrence, G. J., Catanzariti, A. M., Teh, T., Wang, C. I., Ayliffe, M. A., Kobe, B., and Ellis, J. G. 2006. Direct protein interaction underlies gene-for-gene specificity and coevolution of the flax resistance genes and flax rust avirulence genes. Proc. Natl. Acad. Sci. U.S.A. 103:8888-8893.

Dou, D., Kale, S. D., Wang, X., Chen, Y., Wang, Q., Jiang, R. H., Arredondo, F. D., Anderson, R. G., Thakur, P. B., McDowell, J. M., Wang, Y., and Tyler, B. M. 2008. Conserved C-terminal motifs required for avirulence and suppression of cell death by Phytophthora sojae effector Avr1b. Plant Cell 20:1118-1133.

Elmore, J. M., Lin, Z. J., and Coaker, G. 2011. Plant NB-LRR signaling: Upstreams and downstreams. Curr. Opin. Plant Biol. 14:365-371.

Engelhardt, S., Boevink, P. C., Armstrong, M. R., Ramos, M. B., Hein, I., and Birch, P. R. 2012. Relocalization of late blight resistance protein $\mathrm{R} 3 \mathrm{a}$ to endosomal compartments is associated with effector recognition and required for the immune response. Plant Cell 24:5142-5158.

Ewing, B., and Green, P. 1998. Base-calling of automated sequencer traces using phred. II. Error probabilities. Genome Res. 8:186-194.

Farnham, G., and Baulcombe, D. C. 2006. Artificial evolution extends the spectrum of viruses that are targeted by a disease-resistance gene from potato. Proc. Natl. Acad. Sci. U.S.A. 103:18828-18833.

Fisher, M. C., Henk, D. A., Briggs, C. J., Brownstein, J. S., Madoff, L. C., McCraw, S. L., and Gurr, S. J. 2012. Emerging fungal threats to animal, plant and ecosystem health. Nature 484:186-194.

Foster, S. J., Park, T. H., Pel, M., Brigneti, G., Sliwka, J., Jagger, L., van der Vossen, E., and Jones, J. D. 2009. Rpi-vnt1.1, a Tm-2(2) homolog from Solanum venturii, confers resistance to potato late blight. Mol. Plant-Microbe Interact. 22:589-600.

Fry, W. E. 2008. Phytophthora infestans: The plant (and $R$ gene) destroyer. Mol. Plant Pathol. 9:385-402.

Fry, W. E., and Goodwin, S. B. 1997. Re-emergence of potato and tomato late blight in the United States. Plant Dis. 81:1349-1357.

Haas, B. J., Kamoun, S., Zody, M. C., Jiang, R. H., Handsaker, R. E., Cano, L. M., Grabherr, M., Kodira, C. D., Raffaele, S., Torto-Alalibo, T., Bozkurt, T. O., Ah-Fong, A. M., Alvarado, L., Anderson, V. L., Armstrong, M. R., Avrova, A., Baxter, L., Beynon, J., Boevink, P. C., Bollmann, S. R., Bos, J. I., Bulone, V., Cai, G., Cakir, C., Carrington, J. C., Chawner, M., Conti, L., Costanzo, S., Ewan, R., Fahlgren, N., Fischbach, M. A., Fugelstad, J., Gilroy, E. M., Gnerre, S., Green, P. J., Grenville-Briggs, L. J., Griffith, J., Grunwald, N. J., Horn, K., Horner, N. R., Hu, C. H., Huitema, E., Jeong, D. H., Jones, A. M., Jones, J. D. 
Jones, R. W., Karlsson, E. K., Kunjeti, S. G., Lamour, K., Liu, Z., Ma, L., Maclean, D., Chibucos, M. C., McDonald, H., McWalters, J., Meijer, H. J., Morgan, W., Morris, P. F., Munro, C. A., O’Neill, K., OspinaGiraldo, M., Pinzon, A., Pritchard, L., Ramsahoye, B., Ren, Q., Restrepo, S., Roy, S., Sadanandom, A., Savidor, A., Schornack, S., Schwartz, D. C., Schumann, U. D., Schwessinger, B., Seyer, L., Sharpe, T., Silvar, C., Song, J., Studholme, D. J., Sykes, S., Thines, M., van de Vondervoort, P. J., Phuntumart, V., Wawra, S., Weide, R., Win, J., Young, C., Zhou, S., Fry, W., Meyers, B. C., van West, P., Ristaino, J., Govers, F., Birch, P. R., Whisson, S. C., Judelson, H. S., and Nusbaum, C. 2009. Genome sequence and analysis of the Irish potato famine pathogen Phytophthora infestans. Nature 461:393-398.

Hao, W., Collier, S. M., Moffett, P., and Chai, J. 2013. Structural basis for the interaction between the Potato virus $X$ resistance protein (Rx) and its co-factor Ran GTPase-activating protein 2 (RanGAP2). J. Biol. Chem. 288:35868-35876.

Harris, C. J., Slootweg, E. J., Goverse, A., and Baulcombe, D. C. 2013. Stepwise artificial evolution of a plant disease resistance gene. Proc. Natl. Acad. Sci. U.S.A. 110:21189-21194

Haverkort, A. J., Boonekamp, P. M., Hutten, R. C. B., Jacobsen, E., Lotz, L. A. P., Kessel, G. J. T., Visser, R. G. F., and van der Vossen, E. A. G. 2008. Societal costs of late blight in potato and prospects of durable resistance through cisgenic modification. Potato Res. 51:47-57.

Heidrich, K., Blanvillain-Baufume, S., and Parker, J. E. 2012. Molecular and spatial constraints on NB-LRR receptor signaling. Curr. Opin. Plant Biol. 15:385-391.

Hellens, R., Mullineaux, P., and Klee, H. 2000. Technical Focus: A guide to Agrobacterium binary Ti vectors. Trends Plant Sci. 5:446-451.

Hogenhout, S. A., Van der Hoorn, R. A., Terauchi, R., and Kamoun, S. 2009. Emerging concepts in effector biology of plant-associated organisms. Mol. Plant-Microbe Interact. 22:115-122.

Hu, Z., Yan, C., Liu, P., Huang, Z., Ma, R., Zhang, C., Wang, R., Zhang, Y., Martinon, F., Miao, D., Deng, H., Wang, J., Chang, J., and Chai, J. 2013. Crystal structure of NLRC4 reveals its autoinhibition mechanism. Science 341:172-175.

Huang, S., van der Vossen, E. A., Kuang, H., Vleeshouwers, V. G., Zhang, N., Borm, T. J., van Eck, H. J., Baker, B., Jacobsen, E., and Visser, R. G. 2005. Comparative genomics enabled the isolation of the R3a late blight resistance gene in potato. Plant J. 42:251-261.

Jacob, F., Vernaldi, S., and Maekawa, T. 2013. Evolution and conservation of plant NLR functions. Front. Immunol. 4:297.

Jones, J. D. G., and Dangl, J. L. 2006. The plant immune system. Nature 444:323-329

Jupe, F., Pritchard, L., Etherington, G. J., Mackenzie, K., Cock, P. J. A., Wright, F., Sharma, S. K., Bolser, D., Bryan, G. J., Jones, J. D. G., and Hein, I. 2012. Identification and localisation of the NB-LRR gene family within the potato genome. BMC Genomics 13:75.

Kamoun, S., Huitema, E., and Vleeshouwers, V. G. 1999. Resistance to oomycetes: A general role for the hypersensitive response? Trends Plant Sci. 4:196-200

Karimi, M., Inze, D., and Depicker, A. 2002. GATEWAY vectors for Agrobacterium-mediated plant transformation. Trends Plant Sci. 7:193-195.

Kelley, L. A., and Sternberg, M. J. E. 2009. Protein structure prediction on the Web: A case study using the Phyre server. Nat. Protocols 4:363-371.

Kroon, L. P. N. M., Brouwer, H., de Cock, A. W. A. M., and Govers, F. 2011. The genus Phytophthora anno 2012. Phytopathology 102:348364.

Lamour, K. H., Stam, R., Jupe, J., and Huitema, E. 2012. The oomycete broad-host-range pathogen Phytophthora capsici. Mol. Plant Pathol. 13:329-337.

Li, J.-F., Norville, J. E., Aach, J., McCormack, M., Zhang, D., Bush, J., Church, G. M., and Sheen, J. 2013. Multiplex and homologous recombination-mediated genome editing in Arabidopsis and Nicotiana benthamiana using guide RNA and Cas9. Nat. Biotechnol. 31:688-691.

Lu, R., Martin-Hernandez, A. M., Peart, J. R., Malcuit, I., and Baulcombe, D. C. 2003. Virus-induced gene silencing in plants. Methods 30:296303

Lukasik, E., and Takken, F. L. 2009. STANDing strong, resistance proteins instigators of plant defence. Curr. Opin. Plant Biol. 12:427-436.

Maekawa, T., Cheng, W., Spiridon, L. N., Toller, A., Lukasik, E., Saijo, Y., Liu, P., Shen, Q. H., Micluta, M. A., Somssich, I. E., Takken, F. L. Petrescu, A. J., Chai, J., and Schulze-Lefert, P. 2011a. Coiled-coil domain-dependent homodimerization of intracellular barley immune receptors defines a minimal functional module for triggering cell death. Cell Host Microbe 9:187-199.

Maekawa, T., Kufer, T. A., and Schulze-Lefert, P. 2011b. NLR functions in plant and animal immune systems: So far and yet so close. Nat. Immunol. 12:817-826.

Morgan, W., and Kamoun, S. 2007. RXLR effectors of plant pathogenic oomycetes. Curr. Opin. Microbiol. 10:332-338.
Mussolino, C., and Cathomen, T. 2013. RNA guides genome engineering. Nat. Biotechnol. 31:208-209.

Nekrasov, V., Staskawicz, B., Weigel, D., Jones, J. D. G., and Kamoun, S. 2013. Targeted mutagenesis in the model plant Nicotiana benthamiana using Cas9 RNA-guided endonuclease. Nat. Biotechnol. 31:691-693.

Pel, M. A., Foster, S. J., Park, T. H., Rietman, H., van Arkel, G., Jones, J. D., Van Eck, H. J., Jacobsen, E., Visser, R. G., and Van der Vossen, E. A. 2009. Mapping and cloning of late blight resistance genes from Solanum venturii using an interspecific candidate gene approach. Mol. Plant-Microbe Interact. 22:601-615.

Rietman, H., Bijsterbosch, G., Cano, L. M., Lee, H.-R., Vossen, J. H., Jacobsen, E., Visser, R. G. F., Kamoun, S., and Vleeshouwers, V. G. A. A. 2012. Qualitative and quantitative late blight resistance in the potato cultivar Sarpo Mira is determined by the perception of five distinct RXLR effectors. Mol. Plant-Microbe Interact. 25:910-919.

Sambrook, J., and Russell, D. W. 2001. Molecular Cloning. Cold Spring Harbor Laboratory Press, Cold Spring Harbor, New York, U.S.A.

Schornack, S., Moscou, M. J., Ward, E. R., and Horvath, D. M. 2013. Engineering plant disease resistance based on TAL effectors. Annu. Rev. Phytopathol. 51:383-406.

Shan, Q., Wang, Y., Li, J., Zhang, Y., Chen, K., Liang, Z., Zhang, K., Liu, J., Xi, J. J., Qiu, J.-L., and Gao, C. 2013. Targeted genome modification of crop plants using a CRISPR-Cas system. Nat. Biotechnol. 31:686688.

Steinbrenner, A. D., Goritschnig, S., Krasileva, K. V., Schreiber, K. J., and Staskawicz, B. J. 2012. Effector recognition and activation of the Arabidopsis thaliana NLR innate immune receptors. Cold Spring Harb. Symp. Quant. Biol. 77:249-257.

Stirnweis, D., Milani, S. D., Jordan, T., Keller, B., and Brunner, S. 2013. Substitutions of two amino acids in the nucleotide-binding site domain of a resistance protein enhance the hypersensitive response and enlarge the PM3F resistance spectrum in wheat. Mol. Plant-Microbe Interact. 27:265-276.

Takken, F. L., and Goverse, A. 2012. How to build a pathogen detector: Structural basis of NB-LRR function. Curr. Opin. Plant Biol. 15:375384.

Tyler, B. M., Tripathy, S., Zhang, X., Dehal, P., Jiang, R. H., Aerts, A., Arredondo, F. D., Baxter, L., Bensasson, D., Beynon, J. L., Chapman, J., Damasceno, C. M., Dorrance, A. E., Dou, D., Dickerman, A. W., Dubchak, I. L., Garbelotto, M., Gijzen, M., Gordon, S. G., Govers, F., Grunwald, N. J., Huang, W., Ivors, K. L., Jones, R. W., Kamoun, S., Krampis, K., Lamour, K. H., Lee, M. K., McDonald, W. H., Medina, M., Meijer, H. J., Nordberg, E. K., Maclean, D. J., Ospina-Giraldo, M. D., Morris, P. F., Phuntumart, V., Putnam, N. H., Rash, S., Rose, J. K., Sakihama, Y., Salamov, A. A., Savidor, A., Scheuring, C. F., Smith, B. M., Sobral, B. W., Terry, A., Torto-Alalibo, T. A., Win, J., Xu, Z., Zhang, H., Grigoriev, I. V., Rokhsar, D. S., and Boore, J. L. 2006. Phytophthora genome sequences uncover evolutionary origins and mechanisms of pathogenesis. Science 313:1261-1266.

Umaerus, V., and Umaerus, M. 1994. Inheritance of resistance to late blight. Pages 365-401 in: Potato Genetics. J. E. Bradshaw and G. R. Mackay, eds. CAB International, Oxon, U.K.

van der Hoorn, R. A., and Kamoun, S. 2008. From Guard to Decoy: A new model for perception of plant pathogen effectors. Plant Cell 20:20092017.

van der Hoorn, R. A., Laurent, F., Roth, R., and De Wit, P. J. 2000. Agroinfiltration is a versatile tool that facilitates comparative analyses of Avr9/Cf-9-induced and Avr4/Cf-4-induced necrosis. Mol. PlantMicrobe Interact. 13:439-446.

van Engelen, F. A., Molthoff, J. W., Conner, A. J., Nap, J. P., Pereira, A. and Stiekema, W. J. 1995. pBINPLUS: An improved plant transformation vector based on pBIN19. Transgenic Res. 4:288-290.

van Ooijen, G., van den Burg, H. A., Cornelissen, B. J. C., and Takken, F. L. W. 2007. Structure and function of resistance proteins in solanaceous plants. Annu. Rev. Phytopathol. 45:43-72.

van Ooijen, G., Mayr, G., Kasiem, M. M., Albrecht, M., Cornelissen, B. J., and Takken, F. L. 2008. Structure-function analysis of the NB-ARC domain of plant disease resistance proteins. J. Exp. Bot. 59:1383-1397.

van Ooijen, G., Lukasik, E., Van Den Burg, H. A., Vossen, J. H., Cornelissen, B. J., and Takken, F. L. 2010. The small heat shock protein 20 RSI2 interacts with and is required for stability and function of tomato resistance protein I-2. Plant J. 63:563-572.

Vleeshouwers, V. G., van Dooijeweert, W., Govers, F., Kamoun, S., and Colon, L. T. 2000. The hypersensitive response is associated with host and nonhost resistance to Phytophthora infestans. Planta 210:853-864.

Vleeshouwers, V. G., Raffaele, S., Vossen, J. H., Champouret, N., Oliva, R., Segretin, M. E., Rietman, H., Cano, L. M., Lokossou, A., Kessel, G., Pel, M. A., and Kamoun, S. 2011. Understanding and exploiting late blight resistance in the age of effectors. Annu. Rev. Phytopathol. 49:507-531. 
Wastie, R. L. 1991. Breeding for resistance. In: Advances in Plant Pathology 7: Phytophthora infestans, the Cause of Late Blight of Potato. D. S. Ingram and P. H. Williams, eds. Academic Press, New York.

Win, J., Morgan, W., Bos, J. I. B., Krasileva, K. V., Cano, L. M., Chaparro-Garcia, A., Ammar, R., Staskawicz, B. J., and Kamoun, S. 2007. Adaptive evolution has targeted the C-terminal domain of the RXLR effectors of plant pathogenic oomycetes. Plant Cell 19:2349 2369.

Win, J., Chaparro-Garcia, A., Belhaj, K., Saunders, D. G., Yoshida, K. Dong, S., Schornack, S., Zipfel, C., Robatzek, S., Hogenhout, S. A., and Kamoun, S. 2012a. Effector biology of plant-associated organisms: Concepts and perspectives. Cold Spring Harb. Symp. Quant. Biol. 77:235-247.

Win, J., Krasileva, K. V., Kamoun, S., Shirasu, K., Staskawicz, B. J., and Banfield, M. J. 2012b. Sequence divergent RXLR effectors share a structural fold conserved across plant pathogenic oomycete species. PLoS Pathog. 8:e1002400. Published online.
Wirthmueller, L., Maqbool, A., and Banfield, M. J. 2013. On the front line: Structural insights into plant-pathogen interactions. Nat. Rev. Microbiol. 11:761-776.

Xiang, C. F., Han, P., Lutziger, I., Wang, K., and Oliver, D. J. 1999. A mini binary vector series for plant transformation. Plant Mol. Biol. 40:711717.

Yoshida, K., Schuenemann, V. J., Cano, L. M., Pais, M., Mishra, B., Sharma, R., Lanz, C., Martin, F. N., Kamoun, S., Krause, J., Thines, M., Weigel, D., and Burbano, H. A. 2013. The rise and fall of the Phytophthora infestans lineage that triggered the Irish potato famine. Elife 2:e0731. Published online.

\section{AUTHOR-RECOMMENDED INTERNET RESOURCE}

Food and Agriculture Organization of the United Nations (FAO) website: faostat.fao.org/site/339/default.aspx 